\title{
Improving health care providers' knowledge, attitudes, and practices in reproductive health in rural Romania
}

Elaine Claire Himelfarb

Follow this and additional works at: https://knowledgecommons.popcouncil.org/departments_sbsr-rh

Part of the Demography, Population, and Ecology Commons, International Public Health Commons, Maternal and Child Health Commons, Public Health Education and Promotion Commons, and the Women's Health Commons

How does access to this work benefit you? Let us know!

\section{Recommended Citation}

Himelfarb, Elaine Claire. 2004. "Improving health care providers' knowledge, attitudes, and practices in reproductive health in rural Romania," FRONTIERS Final Report. Washington, DC: Population Council. 


\section{Improving Health Care Providers' Knowledge, Attitudes, and Practices in Reproductive Health in Rural Romania}

Elaine Claire Himelfarb, MPH

Project Concern International/Romania

June 2004

This study was funded by the U.S. AGENCY FOR INTERNATIONAL

DEVELOPMENT (USAID) under the terms of Cooperative Agreement Number HRN-A-00-98-00012-00 and Population Council Subagreement Number AI00.94A. The opinions expressed herein are those of the author and do not necessarily reflect the views of USAID. 


\section{EXECUTIVE SUMMARY}

To support new health reform initiatives undertaken by the Romanian Ministry of Health and Family (MoHF), and in support of the U.S.Agency for International Development (USAID) Romania strategy for improving women's reproductive health, Project Concern International/Romaina (PCI/R) was awarded a two-year grant by USAID to implement a reproductive health care project, Healthy Parents-Healthy Children (HP-HC). This project trained 593 family physicians and nurses in rural dispensaries in techniques to improve pre- and postnatal care. It included training on modern contraception, cervical and breast cancer screening, treating menopause and its symptoms, and the encouragement of healthy lifestyles. In October 2000, the Population Council awarded PCI/R a grant to implement an Operations Research (OR) Project, "Improving Health Care Providers' Knowledge Attitudes and Practices in Reproductive Health in Rural Romania." The goal of the OR project was to test the efficacy of interventions to improve the knowledge, attitudes, and practices (KAP) of rural general practitioners (GP) and nurses who were trained by PCI/R's HP-HC training program and to assess changes in reproductive health knowledge and behavior among community women of reproductive age.

The study was carried out between October 1999 and March 2002 in Cluj, Iasi, and Salaj counties. PCI/R administered and managed the study and contracted with Population Services International (PSI) to carry out the data collection activities and help analyze the results.

\section{Problem Statement}

More than a decade after the Romanian revolution, women continue to struggle under the shadow of the former regime. Accurate information about reproductive health is not readily available and misinformation lingers. Most women remain unaware of preventive health care measures, such as Pap smears, breast self-examinations, and modern contraceptive methods and, as a result, do not seek routine reproductive health and gynecological services. At the same time, a disproportionate number of women have fallen below the poverty line since 1989. The poor reproductive health status of Romanian women, together with limited access to health care services, directly influences both maternal mortality and infant mortality rates. They are among the highest in Europe, and Romanian children tend to be smaller and weaker than their counterparts born elsewhere in the West.

\section{Methods}

$\mathrm{PCI} / \mathrm{R}$ employed a quasi-experimental research design using a non-equivalent control group to assess the effect of two training interventions. One experimental group (Cluj) received the five-day HP-HC training and the Warmline provider training, while the second experimental group (Iasi) received the five-day training course only. Data was compared against a third group (Salaj), in which no interventions occurred. Quantitative and qualitative data collection methods were used to triangulate and to obtain an in-depth understanding of providers' KAP toward selected issues and their impact on clients. PCI/R also conducted a community survey to assess changes in client knowledge, attitudes, and practices to complement information obtained from medical providers. The following indicators were identified during the design phase to measure the success of the program: 
- Percent change in provider knowledge about prenatal care and women's preventive health care services

- Percent of women who complete the recommended number of prenatal visits

- Percent of women who start prenatal care during the first trimester

- Number of women who report use of a family planning method during postpartum period

- Number/percent of women who report they know about Pap smears and who report that they had a Pap smear exam

- Number of women who know about breast self-exams (BSE) and who report performing them

\section{Findings}

Prenatal care. Pre- and post-test scores and in-depth interview results indicate a dramatic increase in the level of knowledge and self-confidence among health care providers. For example, post-test results showed a 28 percent average increase in prenatal knowledge from pre-test scores, while interview findings consistently indicated that providers' level of self-confidence in their professional skills increased as a result of the training. Specific findings show an improved working relationship between doctors and nurses, enhanced communication with patients, a more systematic approach to provision of care, and more consultation time with pregnant women.

Postnatal care. Post-test results showed a 45 percent average increase in knowledge of postnatal care from pre-test scores. All providers emphasized the importance of discussions about exclusive breastfeeding with their patients, usually beginning at the third trimester of pregnancy or earlier. The first in-depth interview indicated that women thought three months was the recommended minimum time to begin exclusive breastfeeding. This figure rose significantly at the second interview. The impact of the PCI/R training on discussing modern contraceptive methods with the patients was consistent, and both healthcare providers and patients appear more comfortable in approaching this issue.

Breast cancer screening. Findings show that all providers consistently found that breast cancer screening and education on breast self-examination were critically important because most patients delay seeing the doctor until they have a serious health problem. Providers reported that breast examinations are now included in the annual exam.

Cervical cancer screening. Findings suggest that lack of patient access to specialist facilities and a poor relationship between the general practitioner (GP) and the obstetrician/gynecologist (OB/Gyn) are the principle barriers to cervical cancer screening among women of reproductive age, especially for rural women.

Menopause. Data suggest that there is a lack of provider knowledge and confidence in recognizing signs and symptoms of menopause and in identifying and prescribing appropriate treatment. Providers identified cultural beliefs as a principal barrier to seeking information and treatment for menopause-related symptoms. More practical and competency-based provider training and technical assistance regarding menopause is required, as well as targeted dissemination of key information. 
Chart review findings. $\mathrm{PCI} / \mathrm{R}$ reviewed prenatal records from a sample of providers in each intervention group to assess changes in the quality and content of prenatal care provided by rural general practitioners and nurses. They considered a sample of prenatal records for women who delivered during the 12-month period prior to training and a sample of charts for those who registered for prenatal care after the training began.

Data from the chart reviews indicated score increases (corresponding to correct inclusion of items to improve pre- and postnatal care) in several selected items including vital statistics, external pelvimetry, identification of probable day of birth, and referral to an $\mathrm{OB} / \mathrm{Gyn}$. There was, however, no overall notable improvement between checklist scores from records for women who were registered before the training and those who were registered after the training.

Warmline provider component. Based on findings from the focus group discussions, the Warmline provider component added minimal value to the overall intervention. For example, many of the health providers did not know how to reach the Warmline provider, and the majority of Warmline providers were unclear about their roles and responsibilities. Lack of experience and insufficient time to prepare Warmline providers about how to support their colleagues and carry out new responsibilities were major weaknesses of this component.

Key results from the community survey. Data show slight increases in registration during the first trimester of pregnancy and in the number of women currently using modern methods of contraception. There was also a significant increase in women performing breast self-examinations.

\section{Conclusions and Lessons Learned}

Conclusions. The study shows that the Healthy Parents-Healthy Children project increased medical knowledge and improved behavior among general practitioners, nurses, and women of reproductive age. Providers demonstrated increased levels of confidence as a result of the $\mathrm{PCI} / \mathrm{R}$ training, leading to improved trust, better monitoring, and stricter adherence to new reproductive health guidelines set forth by the Ministry of Health and Family. Patients were found to have begun taking more control of their reproductive health and were making informed decisions about their health care. Findings also indicated that the Warmline provider component added minimal value to the successes of the HP-HC training program.

Lessons learned. Based on the OR results, PCI/R thoroughly modified the Warmline provider program, further strengthening the program and changing the classroomstyle follow-up courses to one-on-one mentoring provided by reproductive health specialists at the clinic, rather than at the training center. PCI/R also organized a second training of trainers course for Warmline providers to further develop leadership, communication, management, counseling, and facilitation skills. Local coordinators were also trained so they could better administer and supervise the Warmline provider program. Feedback from Warmline providers and their trainees indicates that the Warmline provider has become a much more valuable resource.

$\mathrm{PCI} / \mathrm{R}$ has made many internal changes in how health programs in Romania are designed, implemented, and evaluated. For instance, new programs like "Bridging Services for Romania's Underserved Populations," which is funded by the European 
Union, strives to improve access to sustainable health and social integration through an innovative community-based social and health service delivery model in underserved areas. 


\section{CONTENTS}

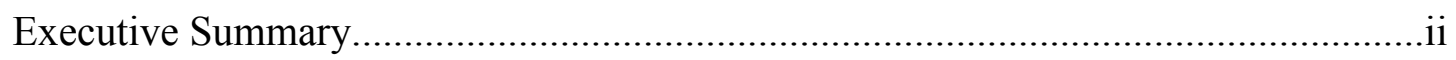

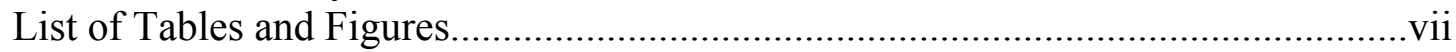

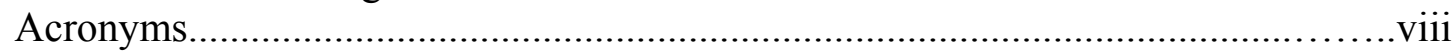

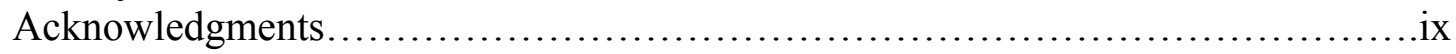

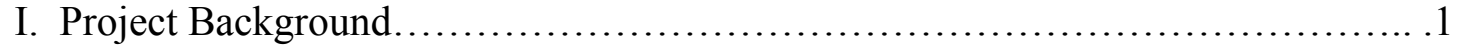

Project Overview.......................................................

Problem Statement......................................................

Location of Study.......................................................

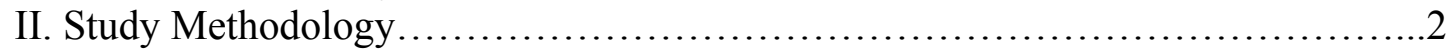

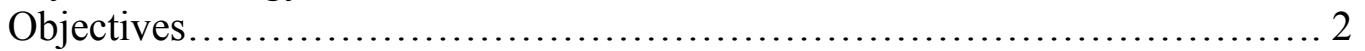

Hypothesis......................................................... 3

Description of Interventions ...........................................

Overall Study Design.................................................. 5

Data Collection Methods and Techniques.................................5

Sampling and Analytic Procedures........................................ 7

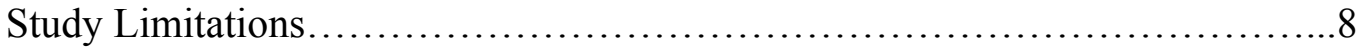

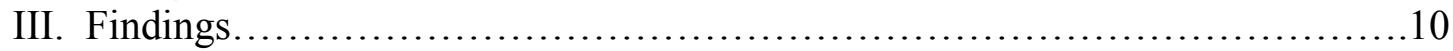

Provider knowledge, attitudes, and practices................................ 10

Pre- and post-training results.......................................... 10

Findings from provider interviews at six and 12-months post training..........11

Findings from the client chart reviews...................................20

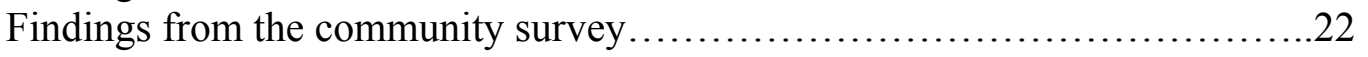

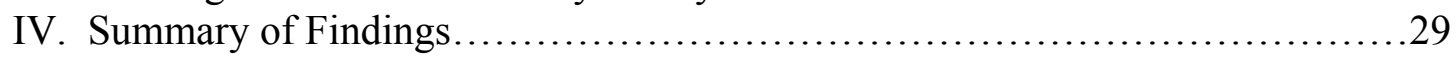

V. Conclusions and Lessons Learned....................................... 30

VI. Recommendations...................................................... 34

Dissemination of Study Results......................................... 34 


\section{LIST OF TABLES AND FIGURES}

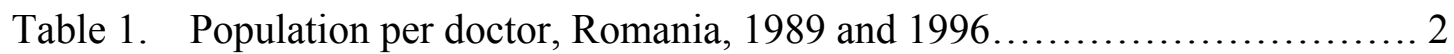

Table 2. Number of training events by intervention group...................... 5

Table 3. Study design in Cluj, Iasi, and Salaj.................................. 5

Table 4. Percentage of women who began prenatal care for last pregnancy in first trimester by selected characteristics at follow-up.................................24

Table 5. Percentage of women using a modern method of contraception by selected characteristics at follow-up................................................. 26

Table 6. Percentage of women who have heard of BSE by selected characteristics at

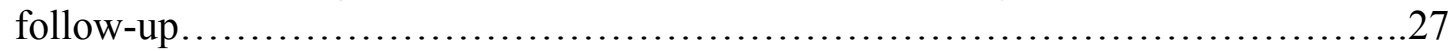

Figure 1. Overall pre- and post-test scores by subject, Iasi and Cluj..............10

Figure 2. Pre- and post-test scores by subject, Group 1 (Cluj).....................11

Figure 3. Pre- and post-test scores by subject, Group 2 (Iasi) .................... 13

Figure 4. First trimester chart review, pre- and post-test, Group 1 (Cluj)............21

Figure 5. Selected characteristics of women at baseline and follow-up.............23

Figure 6. Trimester of pregnancy at first prenatal visit at baseline and follow-up ....24

Figure 7. Percentage of women currently using a family planning method at baseline

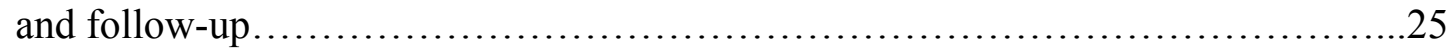

Figure 8. Percentage of women using modern contraception, by method............25

Figure 9. Percentage of women with knowledge about breast self exams at baseline

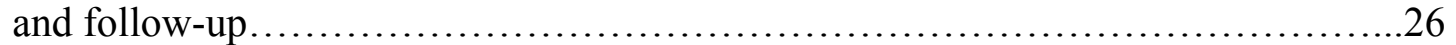

Figure 10. Frequency of BSE among women who have heard about BSE at baseline and follow-up...............................................................27

Figure 11. Percentage of women who have had a cervical cancer screening at baseline and follow-up. .28 


\section{ACRONYMS}

BSE Breast Self-Exam

CDC Centers for Disease Control and Prevention

EU European Union

GP General Practitioner

HP-HC Healthy Parents - Healthy Children

KAP Knowledge, Attitudes, and Practices

MoHF Ministry of Health and Family

NGO Nongovernmental Organization

OB/Gyn Obstetrician/Gynecologist

OR Operations Research

PCI Project Concern International

PCI/R Project Concern International/Romania

PSI Population Services International

RRHS Romania Reproductive Health Survey

SES Socioeconomic Status

STI Sexually Transmitted Infections

ToT Training of Trainers

USAID United States Agency for International Development 


\section{ACKNOWLEDGMENTS}

PCI Romania would like to express its sincere thanks and appreciation to the following individuals for their valuable guidance and support on this project.

Mioara Goia, M.D.: Project Director and Rodica Teodoroiu, M.D.: Local Cluj Coordinator

Ms. Evelyn Landry, MPH: Technical Consultant

Emil Pislaru, Research Coordinator, Population Services International/Romania

Janine Schooley, Susan Gearon and Linda Morales: Project Concern International Office: Final stage comments and suggestions

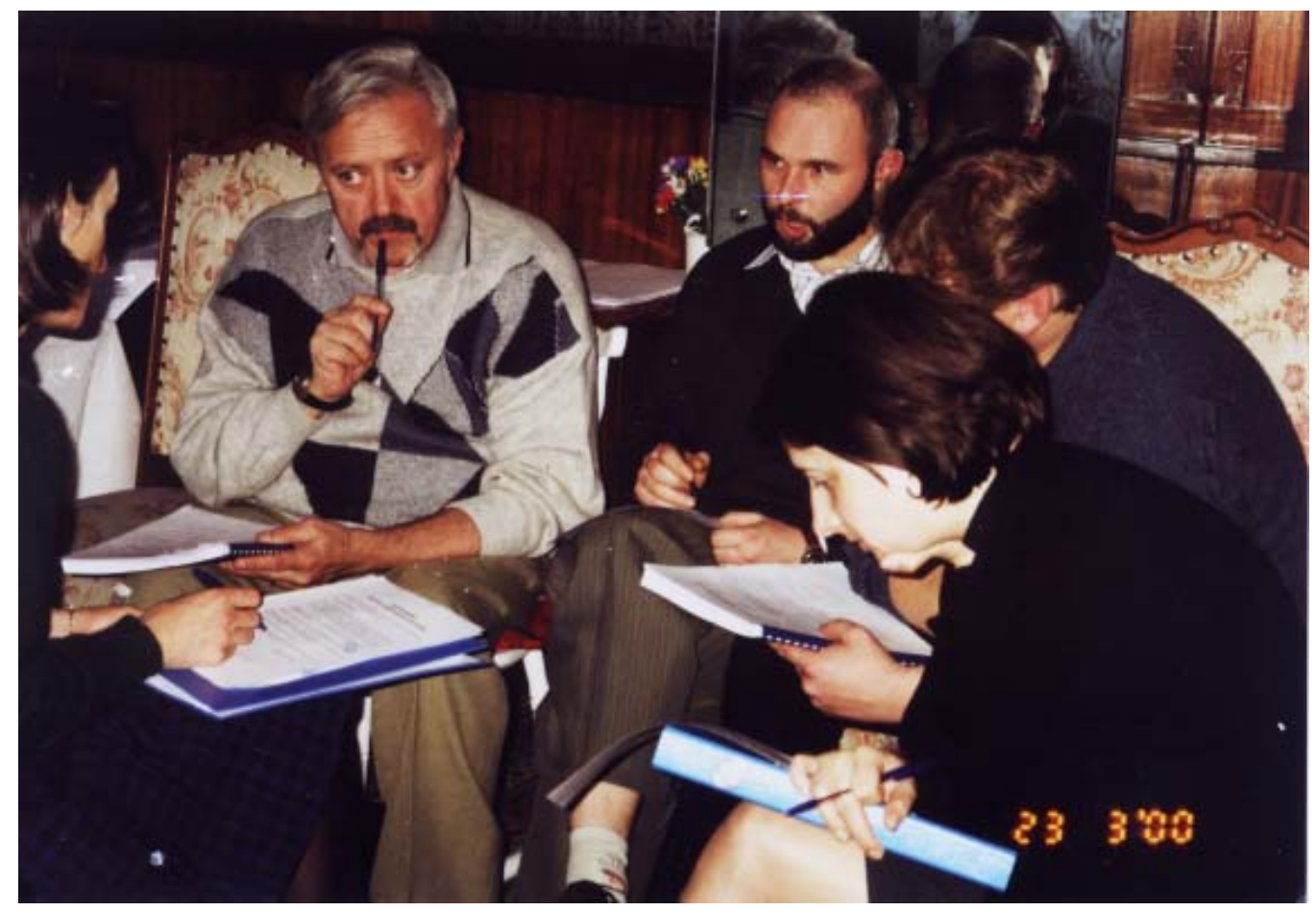

Training of Trainers, Cluj County, March 2000

There are the same problems as before...but I am more aware about the existing risks and about the implications of the risks and I have become more strict, confident and competent in monitoring and treating the pregnant woman.

[Doctor, Cluj, first in-depth interview] 


\section{PROJECT BACKGROUND}

\section{Project Overview}

Since the fall of the former regime in late 1989, health reform has been a priority for the Romanian Ministry of Health and Family (MoHF). To support health reform initiatives undertaken by the MoHF, the U.S. Agency for International Development (USAID) identified projects that could be replicated throughout Romania that would increase the quality of, and demand for, reproductive health care services. In October 1999, USAID awarded Project Concern International/Romaina (PCI/R) a two-year grant to implement a reproductive health care project, Healthy Parents-Healthy Children: Romania's Legacy for the Future. This project trained 593 family physicians and nurses in rural medical clinics on how to improve pre- and postnatal care, and included training on cervical and breast cancer screening, menopause, and the encouragement of healthy lifestyles.

The Population Council awarded PCI/R a grant to implement an Operations Research (OR) project, 'Improving Health Care Providers' Knowledge, Attitudes, and Practices in Reproductive Health in Rural Romania." The goal of the OR project was to test the efficacy of interventions designed to improve the knowledge, attitudes, and practices (KAP) of rural general practitioners (GP) and nurses who were trained by PCI/R's Healthy Parents - Healthy Children (HP-HC) program, as well as changes in reproductive health knowledge and behaviors among community women of reproductive age.

\section{Problem Statement}

More than a decade after the Romanian revolution, women continue to struggle under the shadow of the former regime. Accurate information about reproductive health is not readily available and misinformation lingers. Most women remain unaware of preventive health care measures, such as Pap smears, breast self-examinations, and modern contraceptive methods. As a result, they do not seek routine health and gynecological services. In addition, a disproportionate number of women have fallen below the poverty line since 1989. Economic hardship has led to widespread malnutrition and has hampered government efforts to provide adequate health services. Many women, especially those living in rural areas, lack access to quality health services. These factors contribute to the current health care crisis in Romania.

The poor reproductive health status of Romanian women, together with limited access to health services, directly affects both maternal and infant mortality rates (see Table 1). These rates are amongst the highest in Europe, and Romanian children tend to be smaller and weaker than their counterparts born elsewhere in the West. As of 1999, Romania had the second highest maternal mortality ratio (41.8 deaths per 100,000 live births) among Eastern European countries (the Russian Federation ranks first with 50 deaths per 100,000 live births). The infant mortality rate of 21.5 deaths per 1,000 live births also ranked second highest in Central and Eastern Europe. Most of these deaths occur within the first six days of life, underscoring the need for improved maternal health, nutrition, and pre- and postnatal care.

Furthermore, the Romainian health care crisis is more acute in rural areas (see Table 1). The government no longer requires doctors to serve in remote counties, while rural women cannot afford, nor have access to, gynecologists, who tend to practice in cities. 
Table 1. Population per doctor, Romania, 1989 and 1996

\begin{tabular}{|lcc|}
\hline $\begin{array}{l}\text { Geographic } \\
\text { Setting }\end{array}$ & $\mathbf{1 9 8 9}$ & $\mathbf{1 9 9 9}$ \\
\hline Rural & 971 & 1,698 \\
\hline Urban & 400 & 306 \\
\hline
\end{tabular}

Source: UNDP 2000

To improve the unacceptably high rates of maternal and infant morbidity and mortality, public health programs must promote a comprehensive and effective package of preventive services, including pre- and postnatal care, regular gynecological exams, breast selfexaminations, and information about family planning.

\section{Location of Study}

The research study was undertaken in Cluj in northwest Romania and in Iasi in the northeastern part of the country. Over the past several years, these two counties were selected by USAID as priority areas in which to implement their strategies in reproductive health and child welfare. They are generally comparable to most counties around the country, characterized by poverty, unemployment, underemployment, and poor health outcomes. Salaj, just north of Cluj, was selected as the control site as it shares similar characteristics to Cluj and is geographically accessible.

\section{STUDY METHODOLOGY}

\section{Objectives}

The overall objectives of the Healthy Parents-Healthy Children training program were to increase the effectiveness of reproductive health and family planning services among general practitioners and nurses working in rural areas to increase acceptance, continuation, and consistency of their services.

The objectives of the operations research study were to:

1. Test the efficacy of the Warmline provider program as a complement to a standard training package.

2. Describe provider knowledge, attitudes, and practices regarding selected issues (i.e. prenatal care, postnatal care, cervical cancer, breast exams, menopause, and healthy lifestyles), and describe providers' reported changes in practice after the training.

3. Evaluate consistency over time of providers' knowledge, attitudes, and practices regarding selected issues.

4. Evaluate the impact of providers' practices on the reproductive health of women. 


\section{Hypothesis}

$\mathrm{PCI} / \mathrm{R}$ set out to test the hypothesis that promotion and administration of a quality and comprehensive package of preventive reproductive health services, including pre- and postnatal care, family planning, breast self-examination, cervical cancer screening, menopause counseling, and the encouragement of healthy lifestyles, will create a higher demand for, and consistent use of, reproductive health services among target women in the health service catchment areas.

Furthermore, Experimental Group 1 providers exposed to both interventions (the five-day HP-HC training course and the Warmline provider program) would demonstrate higher performance and better application of new skills than Experimental Group 2 providers who only received the HP-HC training.

\section{Description of Interventions}

The providers selected for the training were general practitioners and nurses from whom women living in rural, isolated areas first seek information. The project trained 593 general practitioners and nurses who work together in rural dispensaries. The vast majority of providers who participated in the training had never been trained in reproductive health issues, despite having worked in rural dispensaries for more than 10 years. After the initial phase of the project, PCI/R improved the program based on the study results, strengthening the Warmline provider program and providing one-on-one mentoring to trained providers in rural dispensaries.

\section{Five-day HP-HC training course for rural general practitioner and nurse teams}

The training focused on improving quality of care in pre- and postnatal care, postpartum family planning, nutrition, and other reproductive health services such as cervical and breast cancer screening, and menopause counseling. The training curriculum was developed by Dr. Cristina Neagu, Director of the National Family Planning Referral Center and Chair of the Bucharest Medical School. It included the new MoHF guidelines and procedures in reproductive health. The 40-hour training was designed to be a practical guide to reproductive health for rural general practitioners and nurses. The curriculum was accredited by both the MoHF and the College of Physicians. Each trainee who completed the course was awarded points to fulfill a requirement to maintain their medical license. Project coordinators in Cluj and Iasi adapted the curriculum to local needs without changing the fundamental components.

Following the development of the curriculum, PCI/R conducted a training of trainers (ToT) course in Iasi and Cluj. A core group of 41 local medical providers were selected as course trainers. They received comprehensive training on both content and on adult learning techniques. The trainers then participated in a screening process in which they were chosen based on their familiarity with the subject matter and their ability to train others utilizing participatory teaching techniques.

Twelve training courses were conducted in both Cluj and Iasi. These five-day courses were conducted between April 2000 and May 2001. Each training event was planned to include16 participants (eight doctor/nurse teams), although the proportion of doctors trained to nurses was two to one. 


\section{Development of Warmline providers}

Inadequate follow-up and application of new knowledge and skills is a universal challenge for training programs. Therefore, $\mathrm{PCI} / \mathrm{R}$ has been experimenting with a methodology to provide ongoing training, mentoring, and support after the initial training period. During the five-day HP-HC training course, a volunteer provider (GP or nurse) was identified through an open selection process to become the Warmline provider for their medical colleagues. The Warmline provider component was intended to provide support, networking, and referrals to colleagues working in rural, isolated dispensaries. PCI/R introduced the Warmline concept to Romania as a way to address the needs of rural providers. Given the staggered manner in which Warmline providers were identified and trained (beginning with PCI/R's first training course in April 2000 and continuing through May 2001), their level of performance has been variable. A total of 21 providers (12 in Cluj and nine in Constanta) ran the Warmline intervention, which included the following activities:

- Provide frequent and ongoing support for fellow trainees in the area through either telephone conversations or meetings to answer questions

- Help providers document the services provided as a result of the training

- Function as a resource for women with complex pregnancies by providing appropriate counseling and referrals on treatment issues

- Communicate to PCI/R the barriers to care and provider needs, and document what is going well, as well as areas of continued difficulty

- Act as a general resource and information person for regional reproductive health and public health events

Building this component into the project from the beginning, PCI/R anticipated that providers in rural areas would have the support and encouragement to apply the course material. It was anticipated that the Warmline providers would continue their roles after the conclusion of the project, thus sustaining the network of support.

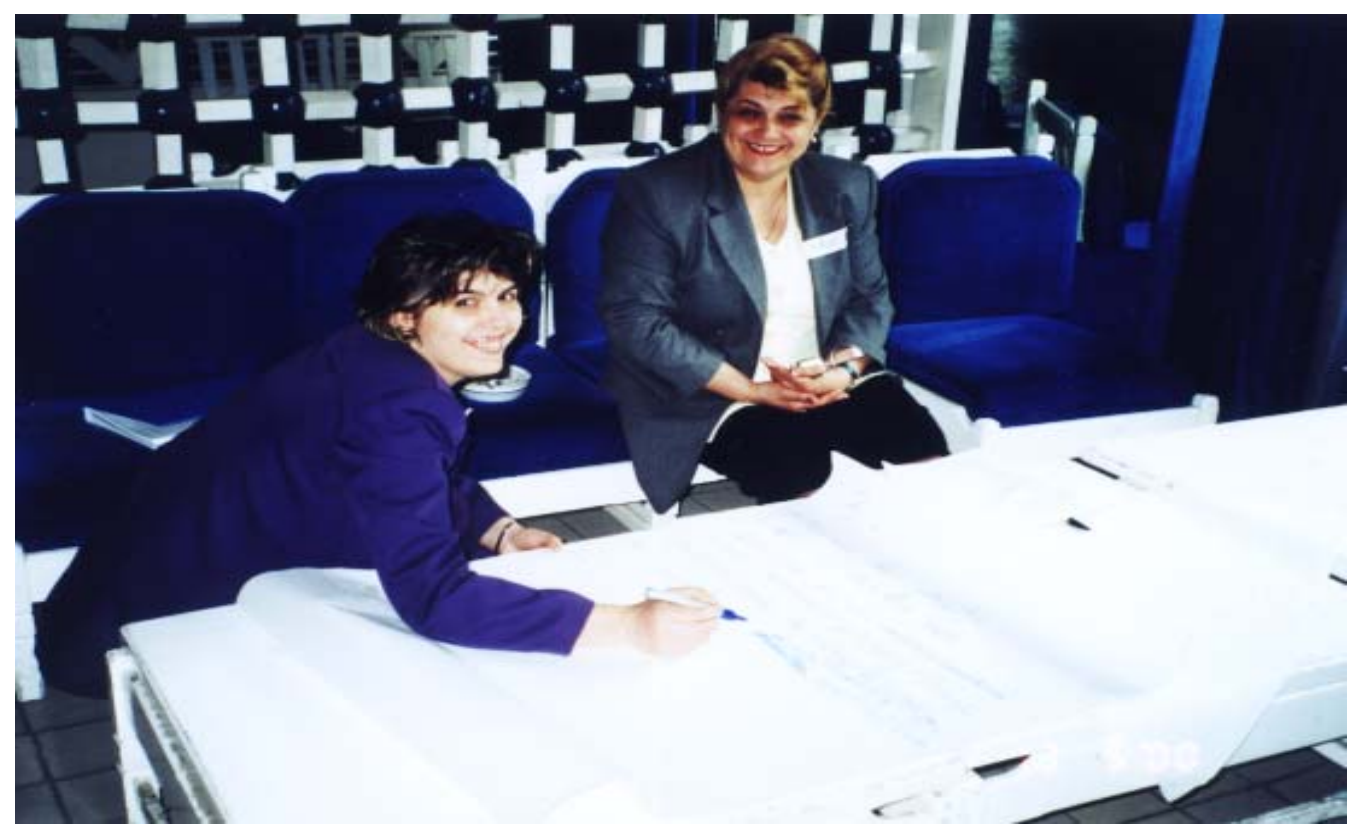

Training participants, Constanta County, May 200

Based on identified needs and problem areas, Warmline providers worked with PCI/R staff to develop 21 eight-hour follow-up training courses, approximately three-six months after 
each training. These sessions were used to reinforce new knowledge, attitudes, and practices introduced in the original training and to answer trainees' questions (see Table 2).

Table 2. Number of training events by intervention group

\begin{tabular}{|l|c|c|c|}
\hline & Group 1: Cluj & Group 2: lasi & Total \\
\hline Number of 40-hour training courses & 12 & 12 & 24 \\
\hline Number of GPs trained & 113 & 116 & 229 \\
\hline Number of nurses trained & 55 & 61 & 116 \\
\hline Number of follow-up courses & 12 & NA & 12 \\
\hline
\end{tabular}

${ }^{*}$ Follow-up training courses were only implemented in Cluj, as one of several components of the Warmline provider intervention

\section{Overall Study Design}

$\mathrm{PCI} / \mathrm{R}$ employed a quasi-experimental research design using a non-equivalent control group to assess the efficacy of two training interventions. One experimental group received the five-day HP-HC training course and the Warmline provider program, while the second experimental group only received the training. Data were compared against a control group, where no interventions occurred.

Table 3. Study design in Cluj, lasi, and Salaj

\begin{tabular}{|l|l|l|}
\hline Study Group & Description & Intervention \\
\hline Group 1: Cluj Area & Experimental & $\begin{array}{l}\text { Training of providers and } \\
\text { Warmline provider intervention }\end{array}$ \\
\hline Group 2: Iasi Area & Experimental & Training of providers \\
\hline Group 3: Salaj Area & Control & No intervention \\
\hline
\end{tabular}

The following indicators were used to measure the effectiveness of the training interventions:

- Percent change in provider knowledge about prenatal care

- Percent change in provider knowledge about women's preventive health care services (BSE, Pap smears)

- Percent of providers who demonstrate appropriate prenatal care services

- Percent of women who complete the recommended number of prenatal visits during their pregnancies

- Percent of women who start prenatal care during the first trimester during their most recent pregnancy

- Number of women who report use of a family planning method during the postpartum period following last pregnancy

- Number of women who report use of a family planning method

- Number/percent of women who report they know about Pap smears

- Number/percent of women who report they have had a Pap smear exam

- Number of women who know about BSE

- Number/percent of women who report they perform BSE

\section{Data Collection Methods and Techniques}

Quantitative and qualitative data collection methods were used for purposes of triangulation and to ascertain an in-depth understanding of both providers' KAP toward selected issues and their impact on clients. Each data collection activity is described below. 


\section{Pre- and post-test questionnaires among training participants}

The initial knowledge, attitudes, and practices surveys were conducted using selfadministered pre- and post-test questionnaires filled out by the participating general practitioners (GPs) and nurses during the training period. The baseline survey was conducted before the training and the final survey was completed at the end of the training. To allow comparison, the same questionnaires were used both in the baseline and the follow-up survey. They contained multiple choice questions and true/false items, and referred to the following issues: prenatal care, postnatal care, breast cancer screening, menopause counseling, and healthy lifestyles. The pre- and post-tests were administered to all training participants. The questionnaire was developed, pre-tested, and finalized by $\mathrm{PCI} / \mathrm{R}$ prior to applying for the OR project. In Cluj, 168 providers completed the pre- and post-tests, and in Iasi, 170 providers finished the tests. In addition, all training participants were requested to complete a simple evaluation form at the conclusion of the training sessions and the follow-up sessions in Cluj.

\section{In-depth interviews among providers at six and 12 months post-training}

In-depth interviews were conducted to identify health care providers' knowledge, attitudes, and practices regarding pre- and postnatal care and other reproductive health care issues. These interviews allowed for a deeper exploration of providers' motivations and behaviors in relation to the training they received from PCI/R. Professional researchers conducted the interviews after reviewing and pre-testing the survey tool. The first in-depth interview was conducted six months after the initial training. The final interview was conducted 12 months after the training. To allow comparison, the same semi-structured guide was used in both interviews. Using the first four months of the training as a base, 50 percent of the providers from Iasi and Cluj were randomly selected for an in-depth interview. In Cluj, the sample consisted of 20 doctors and eight nurses. In Iasi, the sample was comprised of 20 doctors and 10 nurses. The same trainees from Cluj and Iasi who were followed up at six months were assessed again at 12 months.

Providers were initially curious and complied with PCI/R's request for the first round of interviews, which took place either evenings or weekends. During the second round of interviews at 12 months, however, providers were less responsive to the request. Despite the substantial efforts that both PSI and PCI/R staff made to schedule and confirm appointment times in accordance with the providers' preferences for location and time, only 30 percent of respondents attended their appointment. The research staff had to reschedule the interviews several times and often sent the interviewers to rural dispensaries during clinic hours, as this was the only feasible way to meet with the providers and conduct the interviews. Despite this barrier, field teams were eventually able to interview 90 percent of the providers.

\section{Focus group discussions among Warmline providers}

The purpose of the focus groups was to: 1) gain an in-depth understanding of the Warmline providers' activities; 2) assess the impact of this new service among rural providers; and 3) suggest additional interventions that would increase the impact and effectiveness of this innovative component. Three focus group discussions were completed in Cluj and one was held in Iasi. A single moderator facilitated each discussion. PSI used Ethnograph software to analyze the data after it was transcribed and coded, and all focus groups were videotaped after obtaining participants' informed consent. PCI/R tested the focus group discussion guide with several rural GPs and nurses prior to finalization. 


\section{Patient chart reviews}

In order to assess changes in the quality and content of prenatal care provided by rural GPs and nurses, $\mathrm{PCI} / \mathrm{R}$ reviewed patient records from a sample of providers in each intervention group. They selected a sample of prenatal records for women who delivered during the 12month period prior to training and for pregnant women who registered for prenatal care after the training commenced. The chart review took place during the course of the year after the initial training using a pre-tested chart review form. Key indicators recorded from the patient records included: Pap smear testing, referral for blood typing, height, weight, urinalysis, blood pressure, referral for hypertension, referral for type B hepatitis testing, and referral to OB/Gyn. The tool used by PSI was based on the new MoHF standards for the care and treatment of pregnant women. The record reviews were conducted in lieu of patient observations to measure provider practices.

\section{Semi-structured interviews among women of reproductive age}

Assessing the impact of provider training on client behavior is an essential component of any training program and often not included in training evaluation plans. For this OR study, $\mathrm{PCI} / \mathrm{R}$ conducted a community survey of women living in the catchment areas to measure changes in provider knowledge and skills as they influence women's knowledge, attitudes, and practices (KAP) for selected reproductive and family planning issues. PCI/R used data from the 1999 Romanian Reproductive Health Survey (RRHS) as the baseline. ${ }^{1}$ Women's KAP about prenatal care and other preventive and reproductive health issues were measured using a structured questionnaire, based on the one used in the 1999 RRHS. Three broad themes were covered in the survey: pregnancy experience, contraceptive use, and selected health behaviors (e.g., BSE and cervical cancer screening).

\section{Sampling and Analytic Procedures}

Before conducting the data collection for this project, PSI's research team attended two training sessions which included seminars on informed consent protocols, sampling techniques, and analytic procedures.

Simple random sampling was used to select participants for the six and 12 month interviews based on a list of all providers who attended the training during the selected period of time. A more complex sampling design was employed for the community survey to ensure that data would be comparable with the Center for Disease Control and Prevention (CDC) reproductive health survey. The sample was designed to be representative for all women aged 15-44 years. PSI initially developed a sampling frame based on the Romanian population structure, using a stratified sampling design. The first step was to define the strata (geographical variables) and clusters (localities) of the sample. PSI used two variables: county and type of residence (city, town, and rural area). This resulted in nine distinct sub-strata. PSI then randomly selected a number of localities within each sub-strata, in proportion to the total number of localities within the corresponding sub-strata using 1999 data from the national statistics institute. This initial sample raised a logistical problem of several localities having only five or fewer questionnaires completed.

PSI eventually clustered localities according to the geographical strata (county and type of residence). Out of $x$ localities (from the same county, of the same size), each with a number of 1-5 questionnaires would be applied within the premises. PSI randomly selected a half or a third of the numbers and accordingly multiplied the number of questionnaires. 
Finally, the total number of questionnaires within that particular geographical substrata (county combined with type of residence) remained unchanged. Only the number of localities to be visited was lowered.

\section{Study Limitations}

Program objectives were written to demonstrate that the initiatives in the health reform legislation of 1998 were being implemented and were having a positive impact on the quality of women's reproductive health care. At the outset of the training project, however, the research team made a false assumption regarding data collection. They believed that they would have access to the new health insurance reimbursement forms that would detail all the checks and referrals required in pre- and postnatal care. This was not the case, and PSI had to rely on documentation within the patients' charts. In Romania, a culture of accurate and timely patient charting does not exist. It is still illegal for nurses to complete patient files. This places a burden on physicians and reinforces nurses' lack of empowerment. In addition, there are practical problems, such as a lack of paper and pens, in many rural dispensaries. These realities suggest that an alternative data collection method or technique may have been more appropriate for exploring the impact of the $\mathrm{PCI} / \mathrm{R}$ training.

$\mathrm{PCI} / \mathrm{R}$ anticipated that the prenatal patient and provider observation would be implemented during the same time period as the six and 12 month in-depth interviews in Cluj and Iasi. After consulting with the local project coordinators and several rural providers, it became evident that an outside observer evaluating the patient and provider consultation would be intrusive and could potentially alter the course or reults of the consultation. Local medical professionals felt that both the patient and provider would change their behavior significantly as a result of being observed, particularly in rural areas where the providers already have an established rapport with their clients. Based on this rationale, $\mathrm{PCI} / \mathrm{R}$ cancelled the observations and conducted chart reviews and additional focus group discussions.

According to the original proposal, $\mathrm{PCI} / \mathrm{R}$ planned to conduct two focus group discussions with the Warmline providers from Cluj. After much discussion, PCI/R decided that this would be insufficient to properly assess the impact of the Warmline provider. Therefore, $\mathrm{PCI} / \mathrm{R}$ made the following modifications to the plan to more fully understand the impact of the Warmline provider service:

- Conducted a focus group discussion with all of the Warmline providers from Cluj

- Held two focus group discussions with trainees who benefited from the Warmline provider program

- Organized a focus group discussion with trainees in Iasi, where the Warmline component was not part of the $\mathrm{PCI} / \mathrm{R}$ training

Due to a delay in starting the OR study, PSI only had sufficient time to conduct a post-test in Salaj county. Therefore, there is no pre-test data with which to compare results.

The community survey was not designed to focus on community women who received preand postnatal care in the catchment area where the medical providers work. This is because the CDC survey was used as the baseline, and PSI had to use the same sampling frame for the post intervention survey. 
PCI/R staff translated the informed consent forms from English to Romanian and then read the forms to study paticipants. PCI/R preferably should have pretested the consent forms for both readability and comprehension and then modified them appropriately for a rural population unfamiliar with these types of procedures. It was a new concept for researchers to ask permission to pose community members questions and assure confidentiality. 


\section{FINDINGS}

\section{Provider Knowledge, Attitudes, and Practices}

Through the OR study, PCI/R assessed provider KAP on key elements of women's reproductive health. Major findings from the data collection activities are summarized below.

\section{Pre- and post-training results}

The five-day Healthy Parents-Health Children training course was highly effective in increasing participants' knowledge, attitudes, and practices on four out of five selected training themes. Improvements from pre-test to post-test were observed in the areas of prenatal care (28\%), healthy lifestyles (24\%), and breast cancer screening (19\%) (see Figure 1). Sharp increases were found in both counties. All pre-training test results were relatively low; providers answered about half of all questions correctly. The largest increase in providers' knowledge was observed for postnatal care $(45 \%$ increase in correct answers). No increase was found in provider knowledge of menopause. Additional training and assistance needs to be provided to family physicians and nurses regarding all aspects of menopause, including recognizing signs and symptoms and providing treatment. Targeted and pre-tested materials need to be developed and disseminated to the medical community, as well as to community members.

Figure 1. Overall pre- and post- test scores by subject, lasi and Cluj

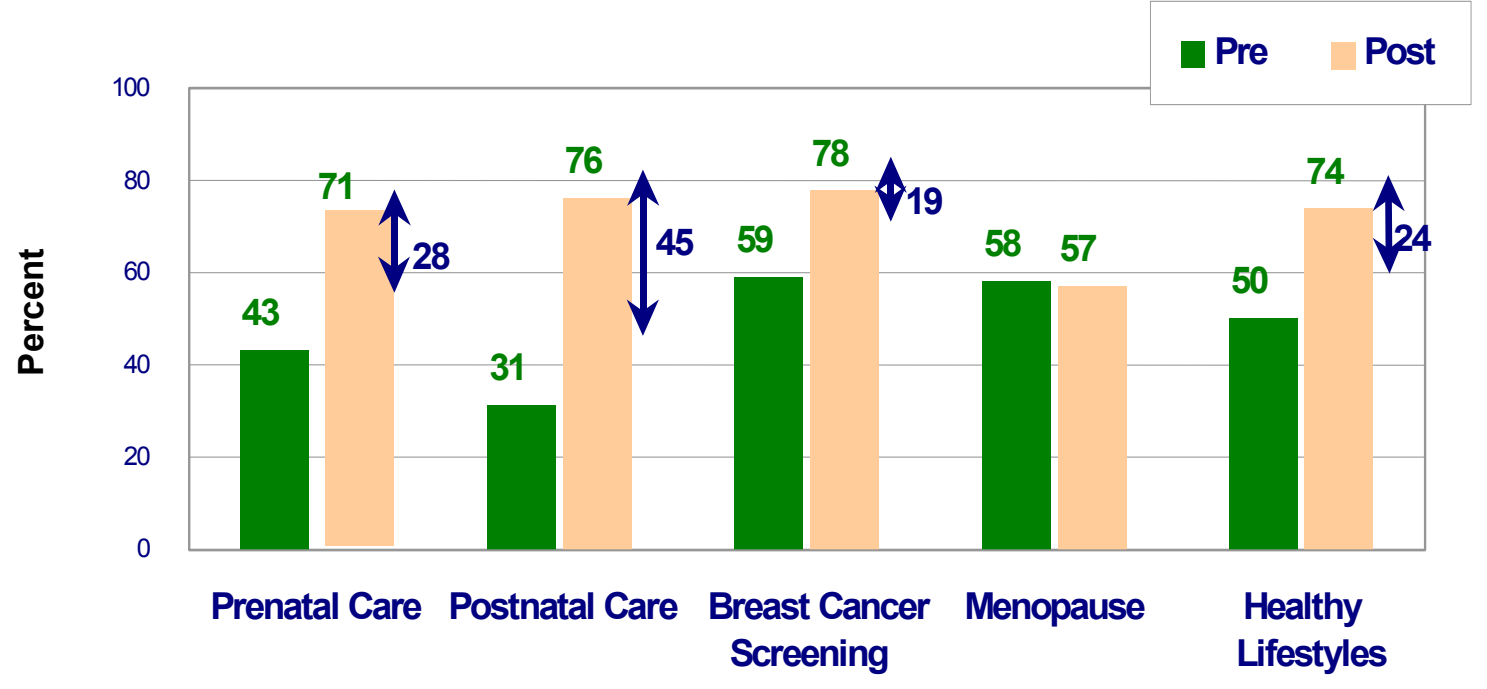


Figure 2. Pre- and post-test scores by subject, Group 1 (Cluj)

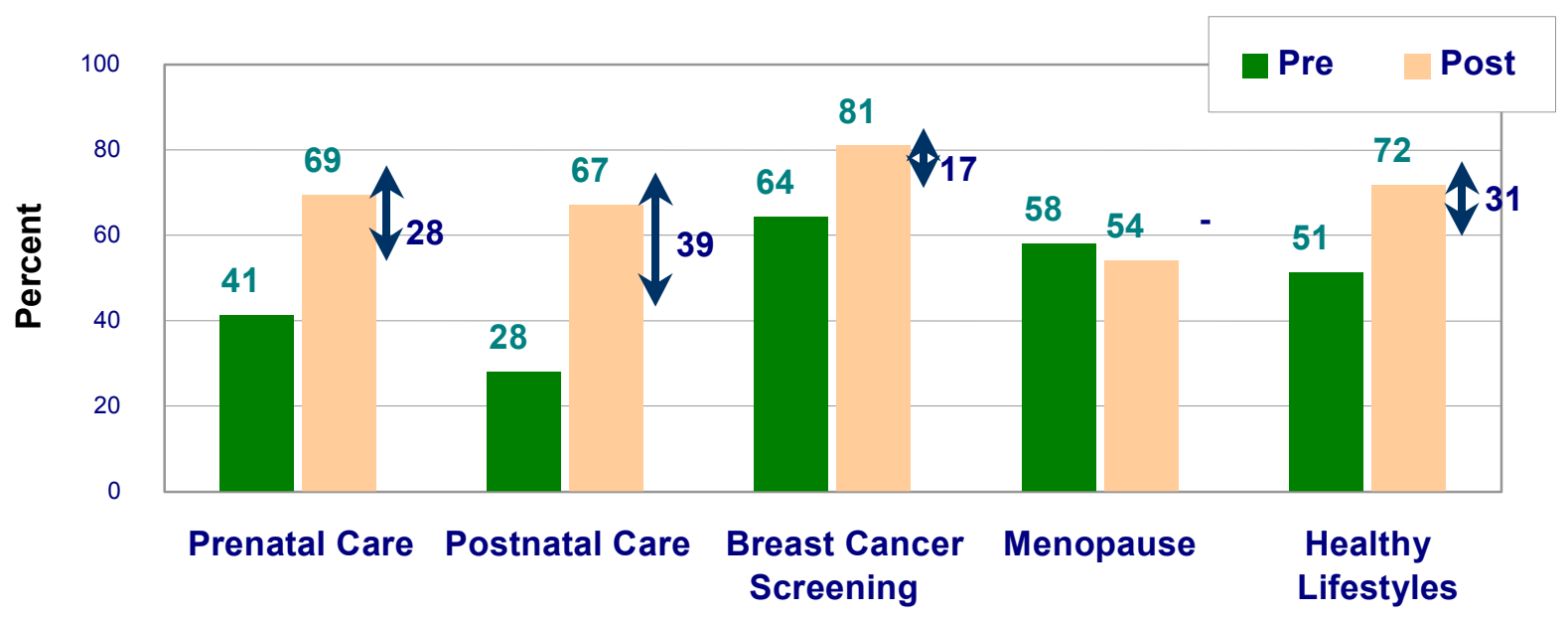

Figure 3. Pre- and post-test scores by subject, Group 2 (lasi)

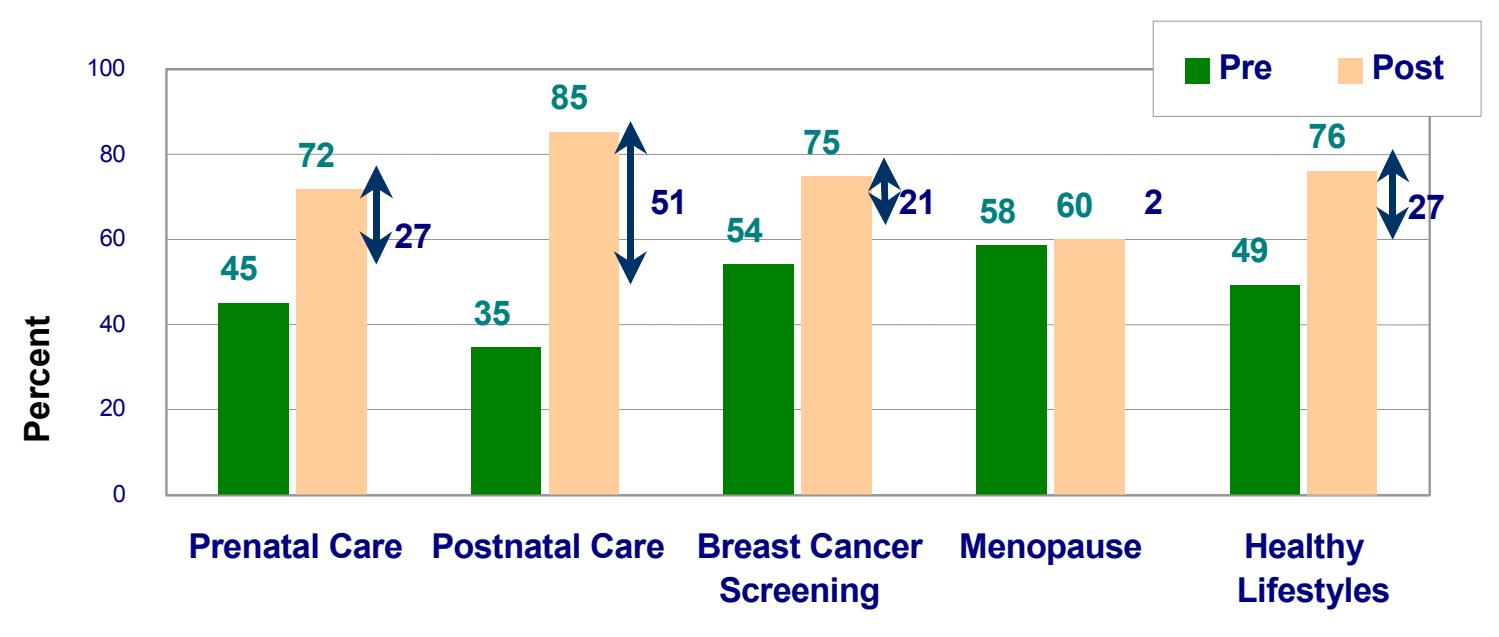

Findings from provider interviews at six and 12 months post training

The purpose of the in-depth interviews was to gather information about providers' self reported change in knowledge, attidues, and practices about six key themes of reproductive health covered in the original training: prenatal care, postnatal care, cervical and breast cancer screening, menopause, and healthy lifestyles.

Prenatal care. When providers were asked if they had changed anything about their practice as a result of the PCI/R training, the vast majority answered positively. Data indicated two broad categories of change regarding care of pregnant women: 1) changes related to specific medical issues (i.e. increase in knowledge of health care issues), and 2) changes related to the interaction with pregnant women (i.e. improved attitude toward clients).

Improvements related to interpersonal relations with pregnant clients were found to be consistent and positive. Providers stated that they were more careful in providing care to 
pregnant women and that their approach became more systematic. The vast majority of providers stated that they spent more time with pregnant clients and felt more selfconfident offering them counseling and treatment.

The data also revealed changes that were not directly related to the training curriculum but were induced by it. Some of the participants, as reported by a doctor interviewed in Iasi, stated that they "stopped watching the clock" and posted a special schedule for pregnant women. Providers also mentioned that they dedicated more time to pregnant clients, which enabled women to receive more information and to have a better understanding of the information provided.

One of the training objectives was to increase the number of pregnant women seen in their first trimester of pregnancy. During the first interview, half of the respondents reported an increase in the number of pregnant women that they saw in the first trimester of their pregnancy compared to the previous year. This occurred because providers stressed the importance of early pregnancy care every time they spoke with patients. Common practices for increasing the number of visits included better communication with patients, approaching patients under all circumstances (e.g. on the street, in the market, and in other public places), sending a nurse to the patient's home, and providing educational materials. Material incentives, for example offering free products such as vitamins, provided another important and effective way to motivate women to visit the doctor during their first trimester. The participants also mentioned that patients who had heard about the training were more trusting of providers and more willing to recommend that colleagues and neighbors visit their doctors.

Interviewers asked providers if they had identified any pregnant women with medical or obstetric high-risk factors that they would not have identified prior to the PCI/R training. During both the first and second in-depth interviews, most practitioners indicated that although they did not identify any new types of risks, as a result of the training they did give more attention to the risks already identified. There were a few providers from both Cluj and Iasi who said that they did learn new risk categories. For example, some practitioners now perceive a pregnant woman to be at risk if her socioeconomic status is extremely low. Providers now treat these women with more confidence, pay more attention to them on a daily basis, and send them to specialists for further care, as needed. As a result of this increased attention, most high-risk pregnancies were expected to have good outcomes.

Postnatal care. Researchers also examined providers' KAP about postnatal care, including breastfeeding and family planning methods. All providers, without exception and regardless of the first or second in-depth interview, strongly emphasized that they discussed breastfeeding with all of the pregnant women in their practice. A typical comment is quoted below:

"Of course...breastfeeding is a very important issue to discuss and encourage with every pregnant woman." [Nurse, Iasi, first in-depth interview] 


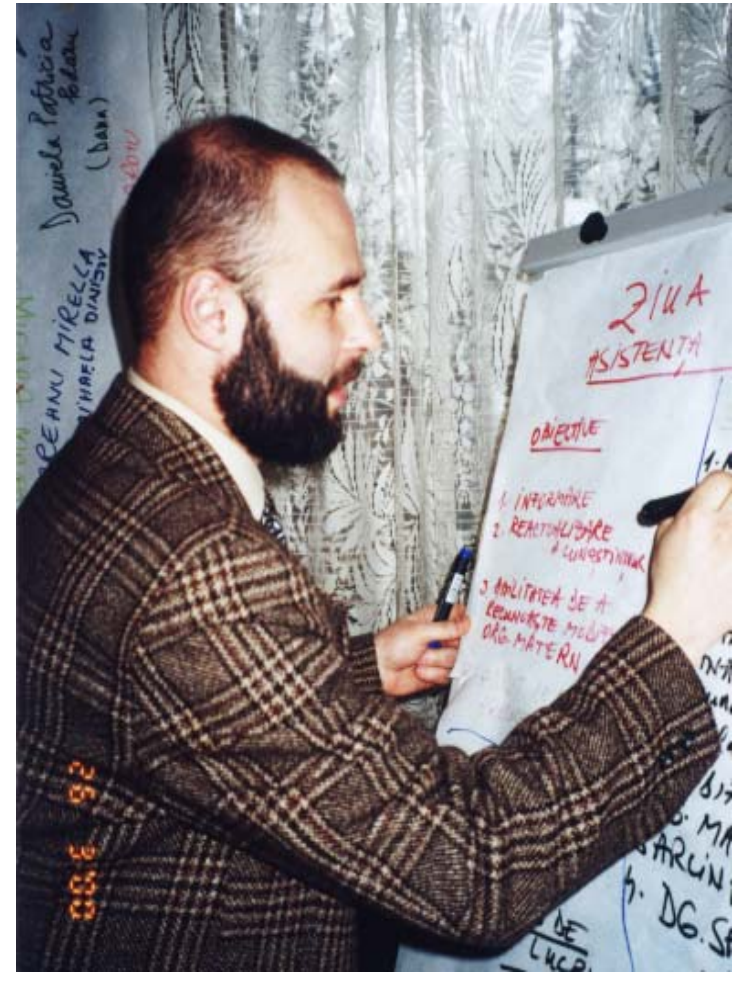

Training of Trainers, Cluj County, March 2000
Most of the participants stated that they usually start counseling pregnant woman about breastfeeding in their third trimester. Some providers indicated that they begin offering information in the second trimester or even on the date that they first see the pregnant woman. During counseling sessions, participants covered a broad range of topics regarding breastfeeding including: 1) information about the advantages of breastfeeding (both for the child and the mother), and 2) specific information about skills and preparation for breastfeeding. The most common information included economic reasons for breastfeeding and quality and quantity of breastmilk. Providers emphasized that breastmilk is best suited to meet the nutritional needs of the newborn child and provides immunity to the child. They also noted that breastfeeding facilitates mother to child bonding, which is critical to the child's further development.

The first in-depth interviews indicated that the minimum time period recommended for breastfeeding was between three months and two years; the most common recommended period was six months. In the second in-depth interview, most providers recommended that breastfeeding continue to 12 months. In the HP-HC training, the norm recommended for exclusive breastfeeding was six months, when complementary feeding should begin, with breastfeeding continuing for as long as mother and baby like.

During both interviews, doctors reported that about 80 percent of young mothers were breastfeeding. The most common reasons given for not breastfeeding were insufficient milk (especially for very young mothers), non-vaginal deliveries, and improper diet due to economic reasons. Stressful conditions or work obligations that require the mother to leave the child were also reasons stated for not breastfeeding. Some participants also referred to the free distribution of powdered milk as discouraging young mothers from breastfeeding. It was reported that occasionally, if providers refused to recommend powered milk, some mothers stopped breastfeeding in order to qualify for it. Doctors adopted different strategies to overcome this problem, presented below:

"Of course I talk about breastfeeding. I have even received notifications that free powdered milk is available, but I don't share it because I don't want my patients to stop breastfeeding." [Doctor, Cluj, second in-depth interview]

"Breastfeeding is the most important thing to discuss with patients. It was very good that the Ministry of Health banned the prescription of free milk, because, unfortunately, this was very damaging. Now, some mothers do not have the economic possibilities to buy milk so they must breastfeed." [Doctor, Cluj, first indepth interview] 
Most of the participants felt more comfortable counseling their clients about family planning methods as a direct result of the training. During the first in-depth interview, with one exception, all providers said they counsel women about the use of modern family planning methods. At the second interview, all informants responded positively. The one participant who initially stated that she "feels embarrassed" stated at the second interview that she now feels more confident talking with her clients about contraceptive methods due to her participation in the training.

Participants were asked to estimate the percentage of young mothers using modern methods of contraception. Providers reported an average of 45 percent both at the first and second interview. Common reasons for not using modern methods were economic or fear of side effects. Other reasons included religious and cultural beliefs and lack of method availability. The most common methods used were IUDs and oral contraceptives. Only a few participants mentioned condoms.

When asked about the most important lesson that providers learned about postnatal care during the training, most mentioned a series of topics instead of just one. The most common subjects mentioned were diet of the mother, breastfeeding, contraception, uterus involution, ${ }^{1}$ monitoring of new mothers, and prophylactic treatment of anemia.

It was evident that postnatal care was an extremely important theme for providers who attended the training. Scores for postnatal care increased more than any other training topic, from 30 percent during the pre-test to 70 percent during the post-test for the two groups combined. In-depth interviews indicate that the vast majority of participants are able to confidently discuss breastfeeding and modern methods of contraception with their clients as a result of the training.

Cervical cancer screening. The study also investigated providers' KAP related to cervical cancer. All participants were asked about the recommended frequency of Pap smear testing. During both the first and second interviews, most respondents stated that this test should be conducted once a year. Of the providers who did not know the ideal time interval for Pap smear testing during the first interview, at the second interview half mentioned once a year as the recommended frequency.

At both interviews, GPs were asked if they had referred any women for Pap smear tests as a result of the PCI/R training. The vast majority of participants indicated that they had referred women to specialists. Providers mentioned several reasons for not recommending a Pap smear test including their belief that only specialists should decide if the test is necessary. Some indicated that they did not know where to send their clients for testing. Others said that they did not refer their clients to specialists because clients would not follow through on the referral. The dichotomy between recommendations and actual client behavior was underlined by several participants who do refer clients for Pap smear tests, as indicated in the following quotes:

"It is documented in the file that, yes, I referred women for Pap test[s] several times... but unfortunately, I know that the women don't get the tests done. The Pap smear is not something known by many women and the financial cost is high. They cannot easily travel to Iasi or Tirgu Frumos for testing, and they hesitate, but the discussion with them exists, especially those with problems. I have told them, and some of them have gone, but some come back only with a clinical exam, not with the test." [Doctor, Iasi, first in-depth interview]

\footnotetext{
${ }^{1}$ Reduction of the uterus to its normal size and state following childbirth
} 
"Yes, I refer women for Pap tests. But they don't go. It is very hard for them. I give them a referral to the specialist and the next month she says, 'My situation is the same. I don't have money this month, as in the previous month." [Doctor, Iasi, first in-depth interview]

Qualitative data revealed that some of the general practitioners felt that specialists discouraged them from sending women for the test. In some circumstances, even if the woman reached the specialist, the specialist did not perform the test:

"Yes, I send my patients, but I don't know if they go or if they do the test. I don't know who is to blame: the client who doesn't go or the specialist that doesn't perform the test." [Doctor, Iasi, first in-depth interview]

"I send women directly to a specialist, but they are not received. The women are seen only if I go with them to the specialist with a specific diagnosis. It is always very crowded at the specialist's office and the women need me to help get them in." [Doctor, Iasi, second in-depth interview]

If a woman returned to her doctor with Pap smear results of Type II or higher, all of the participants indicated that they would send the client to a specialist. While there was no major difference between answers from the first and second in-depth interviews, providers tended to place greater emphasis on their roles as counselors during the second interview. This attitude is exemplified by the pair of quotes below from the same provider during the consecutive interviews:

"First, I explain to her what is on that little piece of paper, and second, I try to make her understand the necessity of treatment, and to go to the specialist...I didn't used to do this, but now I see how important it is." [Doctor, Iasi, first in-depth interview]

"First I explain to her that [it] is not such a disaster as she thinks. They all think this at the beginning, and then I explain what the test is about, and that she has to take care of her health. I also tell her that I will closely monitor her care and try to ease her thinking." [Doctor, Iasi, second in-depth interview]

The data revealed that providers now consistently refer women for Pap smear tests. Despite the referrals, the study found two barriers that prevent women from actually taking the test: 1) the relationship between the general practitioner and the specialist, and 2) the cost of transporting women to the site where the test is performed.

Breast cancer screening. In both interviews, all participants consistently indicated the importance of breast cancer screening. Providers said that the most common reason for promoting breast self-examinations with their clients is because clients can detect, in the early stages, symptoms that might indicate cancer. Participants strongly indicated that it is important for women to know that they can effectively identify problems at no cost beyond the time it takes to perform the exam. They also stated that the incidence of breast cancer has risen dramatically over the last decade. Thus, it is crucial for women to understand how to give themselves breast self-examinations and to perform them on a monthly basis:

"The most important thing is that the cancer is discovered. The woman is the one that can discover it in the earliest stage, the first phase, as no one can examine as good as she can. She knows her body best of all." [Doctor, Iasi, first in-depth interview] 
Participants also pointed out that many clients come to the doctor only when they have a health problem, and thus, it is difficult for the doctor to detect symptoms in the early stages.

All providers stated that they discuss breast self-examination with their female clients and include it in the annual medical exam:

"Yes, it is included in the exam; you cannot check her without a breast exam. There is no discussion about not doing it, it is simply done." [Doctor, Iasi, second in-depth interview]

Doctors were asked what their procedures are for clients who discover a lump in their breasts. Most of the doctors indicated that they had clients who came to them with a detectable lump. In such situations, doctors stated that they confirmed the diagnosis by performing a breast exam and then sent the client to a specialist. Data revealed that providers place equal emphasis on the importance of counseling for Pap smear tests and breast self-exams.

In summary, the data revealed that the participants now consistently present their patients with information about breast self-examinations and discuss the importance of the exam with them. Most of the providers reported that these discussions were effective, as evidenced by clients who self-identified lumps and sought treatment. These women were subsequently referred to specialists for further assistance.

Menopause. The study revealed that providers consider menopause to be very important because it is associated with a series of diseases that appear only during this period, such as osteoporosis and cardiac disease. Also, menopause increases the likelihood of other diseases. Participants stated that several clients who expressed concerns about the symptoms were not fully able to explain them to their providers, and some women seemed afraid about the intensity of the symptoms. For these reasons, participants indicated that it is important to discuss menopause with clients in order for them to recognize and deal with the symptoms appropriately. Typical comments among providers follow:

"It is very important. Because menopause induces a lot of disturbances in the body which the woman is most often not aware of. She thinks that everything is fine up to menopause, so after it will be the same. At menopause, a series of symptoms could be triggered, of which the most frequent is osteoporosis." [Nurse, Cluj, first indepth interview]

While acknowledging the impact of menopause on women's lives, only a few providers reported at the first interview that they prescribed hormonal replacement therapy for their clients. This number rose slightly at the second interview. Still, the majority of doctors consistently choose not to prescribe hormonal replacement therapy themselves, and instead refer women to a specialist. Doctors were not confident prescribing this type of therapy and considered it a specialized form of treatment that requires analysis. Typical comments include the following:

“No, I didn't prescribe it. Usually I send my patients to a specialist. I do not get involved. I mean, I don't hazard myself because it's still a hormonal treatment, and I said to myself, there is no point for the risk." [Doctor, Iasi, second in-depth interview] 
"Because of my own ignorance, I do not prescribe hormonal treatment. That means I do not have this ability. I choose to be involved very little, and refer the women to an endocrinologist." [Doctor, Iasi, first in-depth interview]

A few doctors were not sure if they have the legal right to prescribe hormonal replacement therapy. Others said that it is much easier to send the woman to a specialist. Some said that they do not know the range of hormonal products available. Others emphasized economic reasons for not prescribing it. Even with a prescription, most women could not afford the treatment.

The study documented a lack of awareness both in recognizing the symptoms of menopause and indicating appropriate treatment. Lack of information and confidence in prescribing treatment makes providers reluctant to diagnose symptoms, preferring instead to refer patients to a specialist. Targeted and pre-tested materials need to be developed and disseminated to the medical community, as well as to community members. Along with economic reasons, providers indicated that cultural beliefs are a strong barrier to seeking information and treatment for menopause-related symptoms.

Healthy lifestyles. Researchers were also interested in whether participants discuss alcohol consumption and smoking with their clients, especially during pregnancy. Most of the respondents said they routinely speak with their female clients about both issues, however, some choose not to because their clients would be offended. Other providers choose not to discuss alcohol and smoking because the issues are outside their area of specialization. Other doctors stated that they only discuss alcohol because "it is very hard to discuss smoking when you have a packet of cigarettes on your desk."

Study participants provide a wide range of information regarding healthy pregnancies to their clients, and all providers said that they regularly discuss the negative effects of alcohol and smoking on the fetus. Providers reported that they deliberately choose to scare clients by emphasizing the incidence of cancer and liver problems among those who abuse toxic substances. It was clear from discussants' comments, however, that most clients do not perceive themselves at risk, and the impact of their recommendations is low. One provider said:

"Some of my patients become irritated. They say 'Come on, doctor, are you calling me an alcoholic?' So I formally ask them if they occasionally drink alcohol. But in general everybody is with his or her glass of brandy every day. And the glass is not small.” [Doctor, Iasi, first in-depth interview]

Both the first and second in-depth interviews indicated that providers discuss smoking and alcohol issues with pregnant women. Still, they reached few of their clients with this message. Thus, there is a need to develop creative and varied methods to introduce healthy lifestyles to clients.

\section{Multidisciplinary Teamwork}

GPs and nurses were encouraged to attend the PCI/R training as a team, and almost all participants stated that their work activities improved as a result of this approach.

According to the GPs, the most common benefit from attending the training with a colleague is that they can delegate more responsibilities to the nurses who accompanied them. The nurses can provide support in implementing the new treatments learned at the training. The changes were exemplified in the following quote: 
"Nurses better understand what is expected from them, what is their role. They used to think that they had no role except to call the client and weigh her and under no circumstances give advice like what to eat or other things. And now, they are more interested in monitoring the pregnant woman and even explaining what types of tests are necessary. Nurses now feel confident in explaining to the pregnant women, 'Look, you need those analyses for these reasons, you are not throwing the money out of the window because you can find out about these things." [Doctor, Iasi, second in-depth interview]

Attending the training as a team had a positive impact on providers' service delivery to clients. As a result of the training, GPs were more confident in delegating responsibilities to nurses and in re-evaluating the nurses' responsibilities. Nurses also indicated that they feel more confident and motivated to deliver quality services. This had a positive effect on the clients, who were then more likely to follow instructions given by their health care providers.

\section{Warmline Providers: Trainee Perspective}

Assessing the impact of the Warmline provider on participant services was an important component of the study. Through in-depth interviews and special focus group discussions, researchers questioned providers in Cluj (Group 1) about the role of the Warmline provider. The findings from these two sets of qualitative data exercises are summarized below.

At the first in-depth interview six months following training, only a quarter of respondents stated that they knew the identity of their Warmline provider. By the second round of interviews, half of the providers reported knowing the Warmline provider. GPs were more likely to know who this person was than nurses. Respondents reported that the Warmline provider only contacted them three-five times during the year, usually regarding administrative issues on training follow-up. Providers rarely contacted the Warmline provider for advice about medical issues.

Findings from the focus groups revealed more information about the perceived benefits of this service and actual services provided during this experimental period. In general, participants thought that the role of a Warmline provider should be performed by a highly respected professional in the local medical community. At the same time, this person should have enough time to dedicate to this activity. Participants considered these requirements to be contradictory, as a good GP usually does not have spare time.

Many of the GPs reported that they did not have a clear idea of what to expect from the Warmline provider, as many did not understand the Warmline provider's role. Providers reported that their primary contact with Warmline providers was by phone, and no formal meetings were scheduled.

All participants were asked what they would expect from Warmline providers. The focus groups highlighted four broad roles: 1) to provide specialized information; 2) to monitor implementation of difficult parts of the training and to provide updated information; 3 ) to set a positive example about how to overcome problems; and 4) to facilitate communication and exchange of information between GPs (eg., through roundtables).

"His role would be to keep us lively, because otherwise we will be in the day-to-day routine, consulting every day and forget about the interesting part when you have to 
do something different. So his role will be to send us a stimulus to remind us what are we doing." [Doctor, Cluj, focus group discussion]

The in-depth interviews and focus group discussions with providers in Group 1 revealed little or no impact of the Warmline provider program on the health providers' practices. Even with knowledge about the Warmline provider, GPs, OB/Gyns, and others perceived no added benefit in their KAP. The weaknesses in the program were in part due to the Warmline providers' lack of experience and lack of adequate time to understand how to support their colleagues and carry out their new responsibilities.

\section{Warmline Providers: Their Perspective}

In general, Warmline providers were enthusiastic about performing their new roles. Participants stated it was an excellent opportunity for them to improve the quality of reproductive health services in their county. However, they were unsure about their roles and responsibilities and about the type of information they should provide.

Most of the Warmline providers were unable to estimate the amount of time they spent providing support to other trainees; they admitted that they "do not spend too much time," mostly because they do not have time for "extracurricular" activities. The Warmline providers noted that it was difficult to stay in contact with providers, especially those living in rural areas where telephone service is not reliable. Warmline providers reported initiating contact with trainees, both formally making calls to follow up about any special problems and informally meeting as friends to discuss medical issues. Also, participants said that they take advantage of other meetings with training colleagues to discuss medical problems. However, most of the participants were not able to provide information about the exact number of contacts.

Most of the Warmline providers reported the most commonly requested type of information was on new training courses. They were seen as a link between participants and PCI/R. This role seems to be important, as about half of the Warmline providers said that they were contacted by doctors who had not attended the PCI/R-sponsored training to find out about training opportunities.

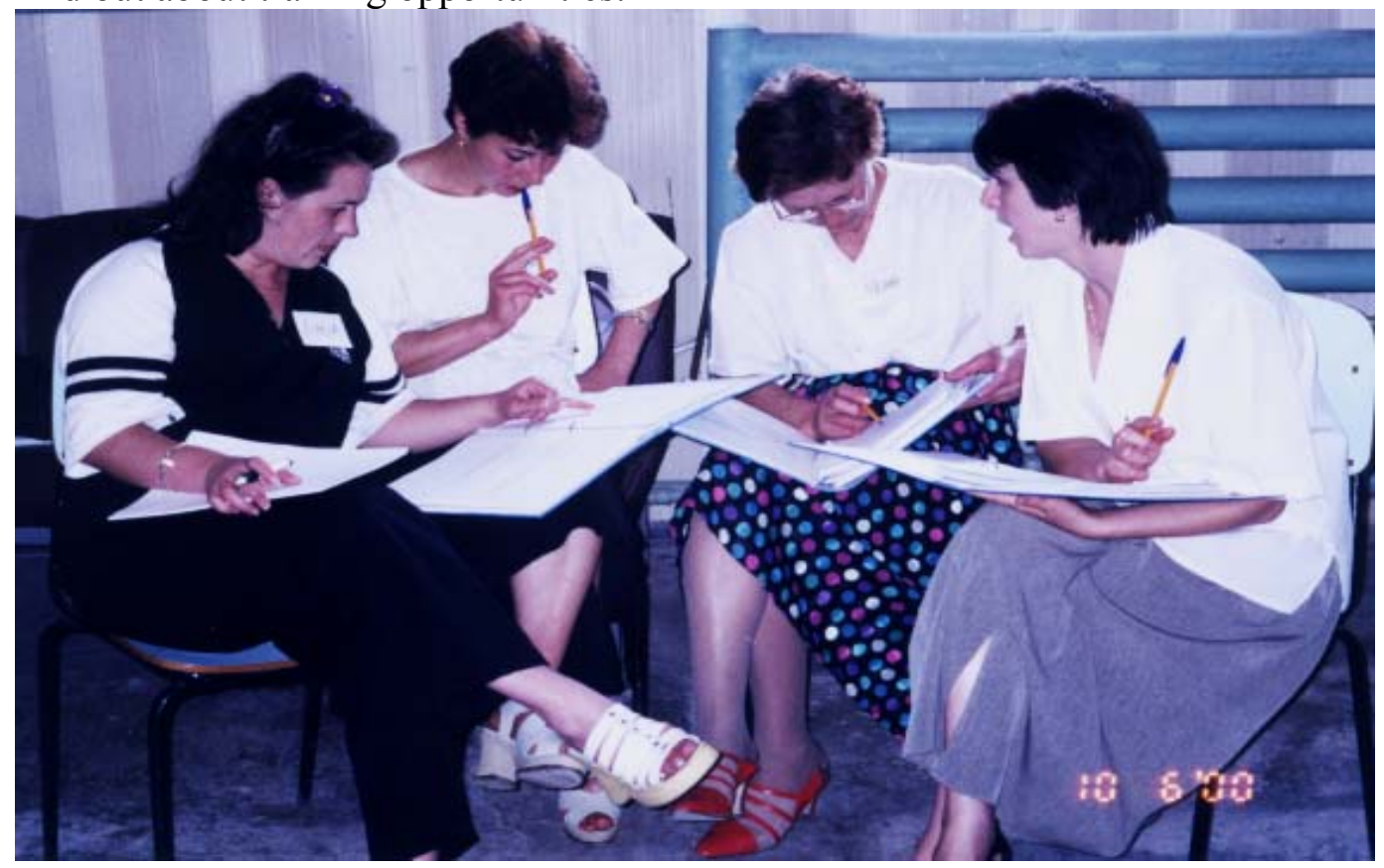

Training Participants, Iasi County, May 2000 


\section{Findings from the client chart reviews}

The overall purpose of the chart review was to assess if providers changed practices related to prenatal care as a result of the PCI/R training interventions. The data were initially analyzed by group (date of register, first, second and third trimester), and then the three groups were compared to each other.

There was no overall significant improvement between scores from records for women who were registered before training and those who were registered after training in any of the project areas. However, significant score increases were found in selected items in the chart reviews including weight, blood pressure, pulse, external pelvimetry, referral to $\mathrm{OB} / \mathrm{Gyn}$, probable day of birth, and dental exam. A particularly positive outcome of the training was the significant increase in referrals to gynecologists in both groups. The training was also effective in increasing the scores for checking women's pulses during all three trimesters of pregnancy.

\section{Date of register}

- In Cluj and Iasi, there was a significant increase from pre- to post-test results in checking pulse, external pelvimetry, and referral to a gynecologist.

- In Salaj, there was a significant decrease in referral for Rh typing. There was no significant decrease in the other groups (Cluj and Iasi).

- In Iasi, there was a significant increase in checking general clinic exam, referral for HB, hypertension, and RBW.

\section{First trimeser}

- In Cluj and Iasi there were significant increases in checking the pulse (4 and 10\%, respectively). There were no other significant differences found.

\section{Second trimester}

- In Cluj and Iasi there were significant increases in checking pulse (15 and 27\%, respectively.

- In Iasi there was a significant decrease in referral for hypertension and referral for hepatitis B testing (down 10\% for both items).

\section{Third trimester}

- In Salaj, there was a significant decrease in services from pre- to post-tests. In Cluj and Iasi the decrease was less, particularly for checking weight and blood pressure.

- In Cluj and Iasi there were significant increases in checking pulse and edema ( $9 \%$ both in Cluj and in Iasi).

- In Salaj there was a significant decrease for all 19 indicators. In Cluj and Iasi the decrease was less, particularly in checking pulse and referral for BCF.

- In Salaj there was no significant decrease in checking DT/ATPA at 36 weeks, but in Cluj and Iasi, there were significant decreases $(9 \%)$.

- In Cluj there was a significant increase ( 7 and $6 \%$, respectively) in checking HB and HT. In Iasi there was a significant decrease in checking the same items $(7 \%$ for HB and $8 \%$ for HT). There were no significant differences in Salaj.

- In Cluj there was a significant increase in the number of visits for the third trimester, IFU, APZ, and D2. 
There was a significant increase in Cluj for checking pulse, edema, hepatitis B testing and hypertension. In the same area, a significant decrease was found for weight, blood pressure, ADTPA, Vitamin D, ecography, OG, RBW, DT/ADTPA, and calcium.

\section{Comparison of overall scores (date of register, first, second, and third trimester)}

Pre-training results indicate that only about one-third of the tests were performed $(33 \%$ in Cluj, 30\% in Iasi, and 29\% in Salaj). There were no increases in the items checked post training (33\% in Cluj, 33\% in Iasi, and 30\% in Salaj).

Figure 4. First trimester chart review, pre- and post-test, Group 1 (Cluj)

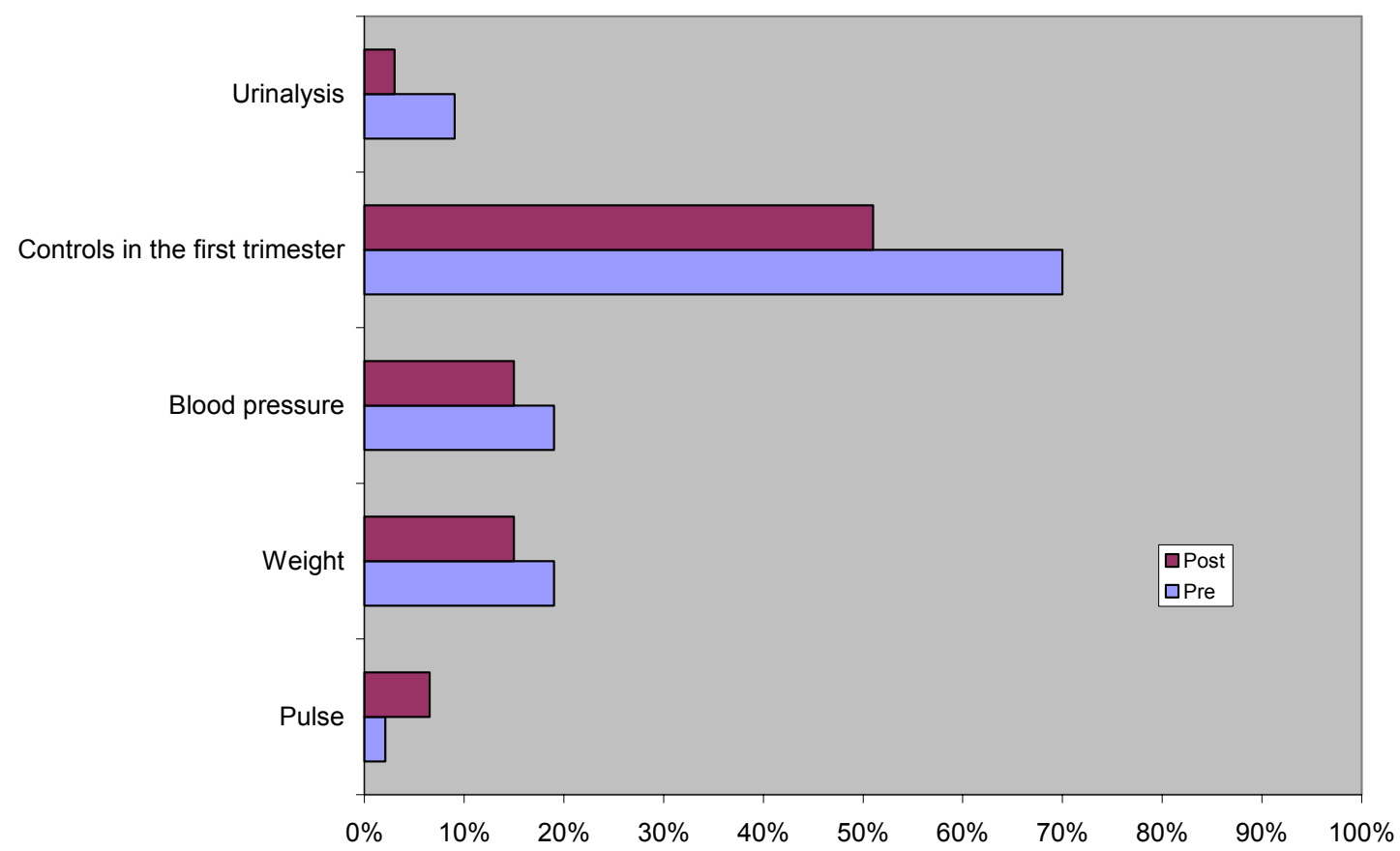

It is not apparent why Cluj did so poorly between pre- and post-test results in selected items, as seen from the above graph. In order to determine why the results were so staggered, PCI/R consulted medical specialists who informed them that it is questionable to use patient charts to document changes in behaviors and treatment. Romania does not yet have a culture of accurate and timely patient charting. Although accurate charting was not a focus of the HP-HC training, PCI/R designed a comprehensive, user-friendly, perinatal monitoring and tracking form that was distributed to all providers in the training packet. Most providers said the form was extremely useful. Unfortunately, many dispensaries lacked the funds to make copies of the form once the originals were exhausted. Because the HP-HC training did not specifically focus on charting, the use of chart reviews should be considered a design flaw of the study. An alternative research method might have shed more light on the impact of the PCI/R training.

Providers must now, for the first time, document statistics on treatment to the Local Insurance House in order to be reimbursed - a documenting skill many have difficulty mastering. The HP-HC program helped train GPs on how to fill out the required forms. Providers were motivated to complete insurance forms properly so that they could be reimbursed. There was no such incentive for documentation in patient charts. Additionally, some providers said they remember medical information about their pregnant patients, which makes patient charting unnecessary. This may indeed be the situation, as the number of pregnancies is relatively small in rural communities, and providers have known 
community members since they were children. There are other problems as well. For instance, it is still illegal for nurses to chart patient histories and many necessary supplies, such as paper and ink, are not available.

\section{Findings from the community survey}

The four key reproductive health areas that the training intervention sought to address included early initiation of prenatal care; use of family planning; knowledge, attitudes, and practices about breast self-exam; and knowledge, attitudes, and practices on cervical cancer screening. Data were collected through interviews with a population-based random sample of women living in the catchment areas where the training interventions took place. PCI/R conducted a community survey in the control area to compare with the KAP survey and to see if there were any significant changes that may have resulted from the training interventions. Key findings include:

- Slight increases were observed among women who reported that they attended their first prenatal visit during the first trimester in both intervention groups. The increases were not significant.

- The percentage of women currently using modern methods of contraception increased slightly in both groups. The highest reported use, however, was in the control group (Salaj).

- The percentage of women with knowledge about breast self-exams significantly increased in both intervention groups between baseline and follow-up. However, knowledge was just as high in the control area.

Demographic characteristics. Figure 5 shows a summary of demographic characteristics among women surveyed in both baseline and follow up surveys for three groups.

- Age: Differences are noted in age distribution between baseline and follow-up surveys. In Cluj the follow-up sample had a younger group of women, while in Iasi, women were slightly older. However, due to the relatively small size of sub samples, it is impossible to say if these differences are significant. Overall, women in the control group (Salaj) are slightly older in the follow-up.

- Education: As with age, slight differences are noted between baseline and follow-up surveys. Overall, women in Cluj and Iasi in the follow-up survey are more educated than women in the control group.

- Socioeconomic Status: Women who were interviewed in the follow-up survey were of higher economic status in Cluj compared to those surveyed in the other two groups. 
Figure 5. Selected characteristics of women at baseline and follow-up

\begin{tabular}{|c|c|c|c|c|}
\hline \multicolumn{2}{|c|}{ Cluj-Group 1 } & \multicolumn{2}{|c|}{ lasi-Group 2 } & Salaj-Group 3 \\
\hline Baseline & Follow-up & Baseline & Follow-up & Follow-up \\
\hline $\mathrm{N}=708$ & $\mathrm{~N}=152$ & $\mathrm{~N}=647$ & $\mathrm{~N}=130$ & $\mathrm{~N}=150$ \\
\hline
\end{tabular}

\section{Age Group}

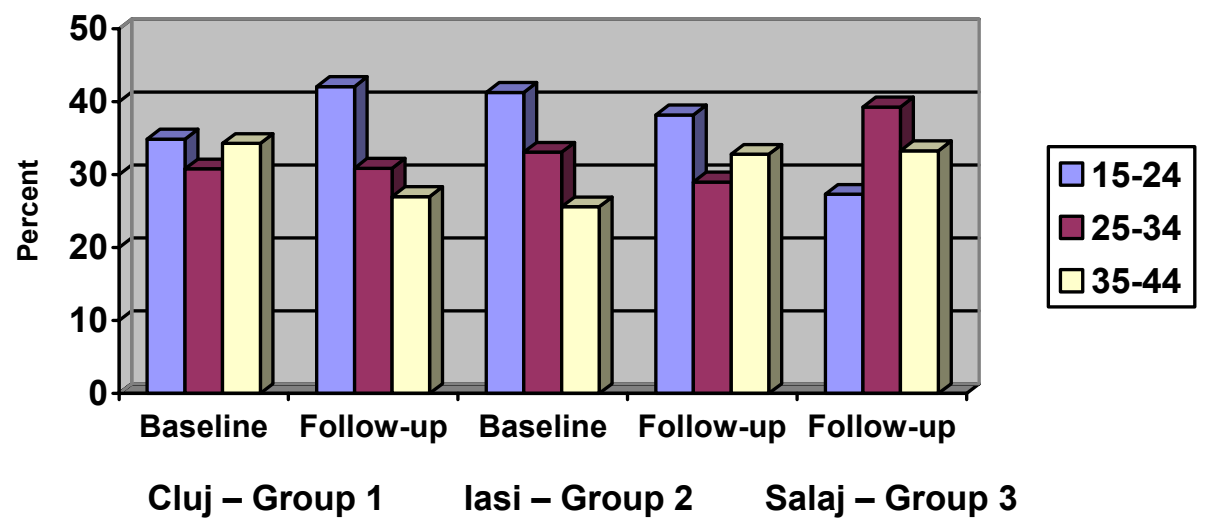

Level of Education

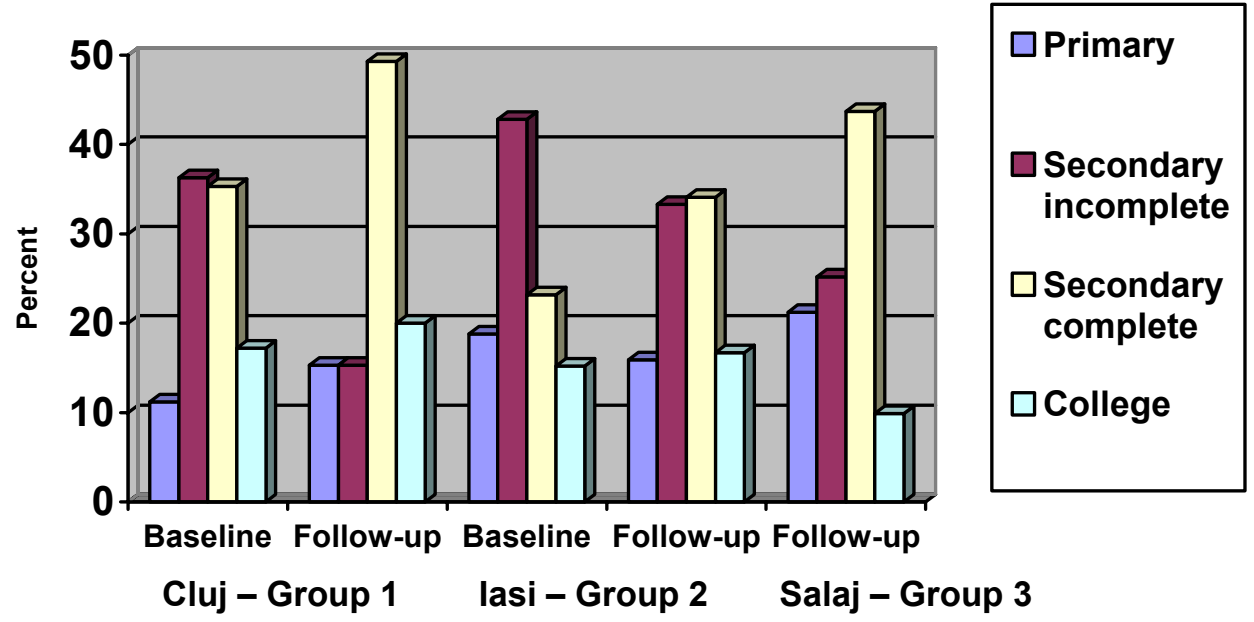

\section{Socioeconomic Status}

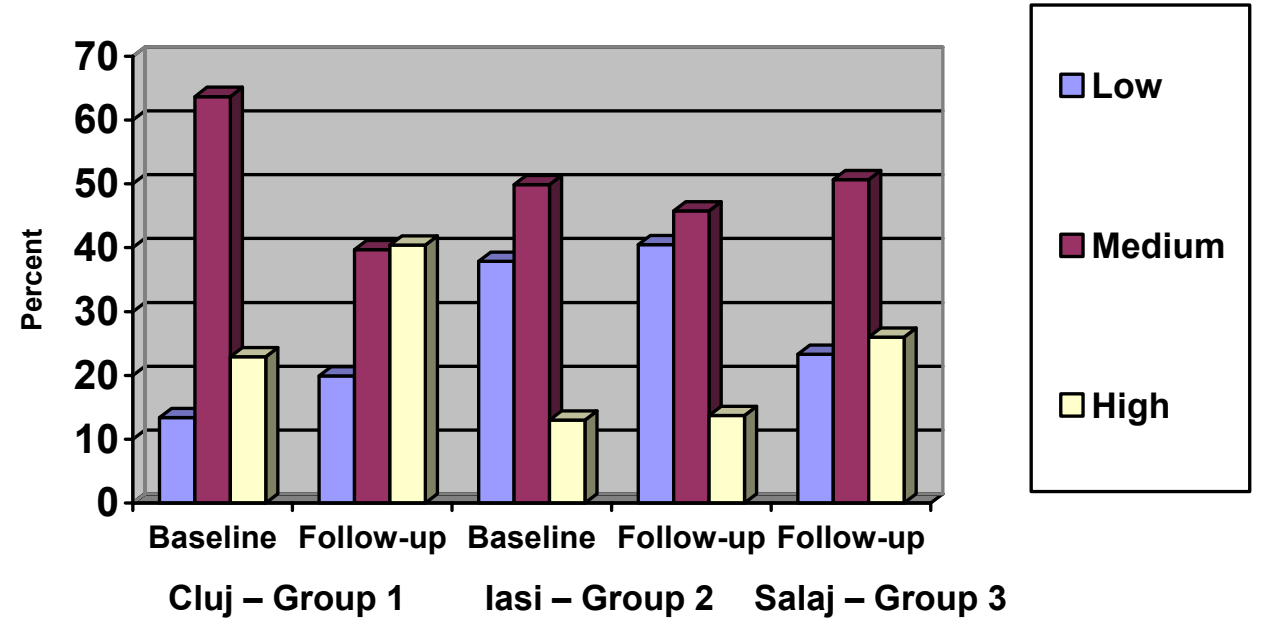

Improving Health Care Providers' KAP in Reproductive Health in Rural Romania 
Prenatal care. One of the primary objectives of the training intervention was to improve the timing of when women first seek prenatal care. Figure 6 shows a comparison between baseline and follow-up surveys for the three study areas: Cluj, Iasi, and Salaj. Compared with the 1999 data, a slight increase was noted in both intervention groups, however, these increases were not significant. Both in the baseline and follow-up surveys, women from the Cluj area were more likely to seek prenatal care in the first trimester $(72 \%)$ than women from Salaj (65\%) and Iasi (59\%). Women with higher levels of education and higher economic status were more likely to start prenatal care in the first trimester across all three groups.

Figure 6. Trimester of pregnancy at first prenatal visits at baseline and follow-up

\section{Prenatal Visits}

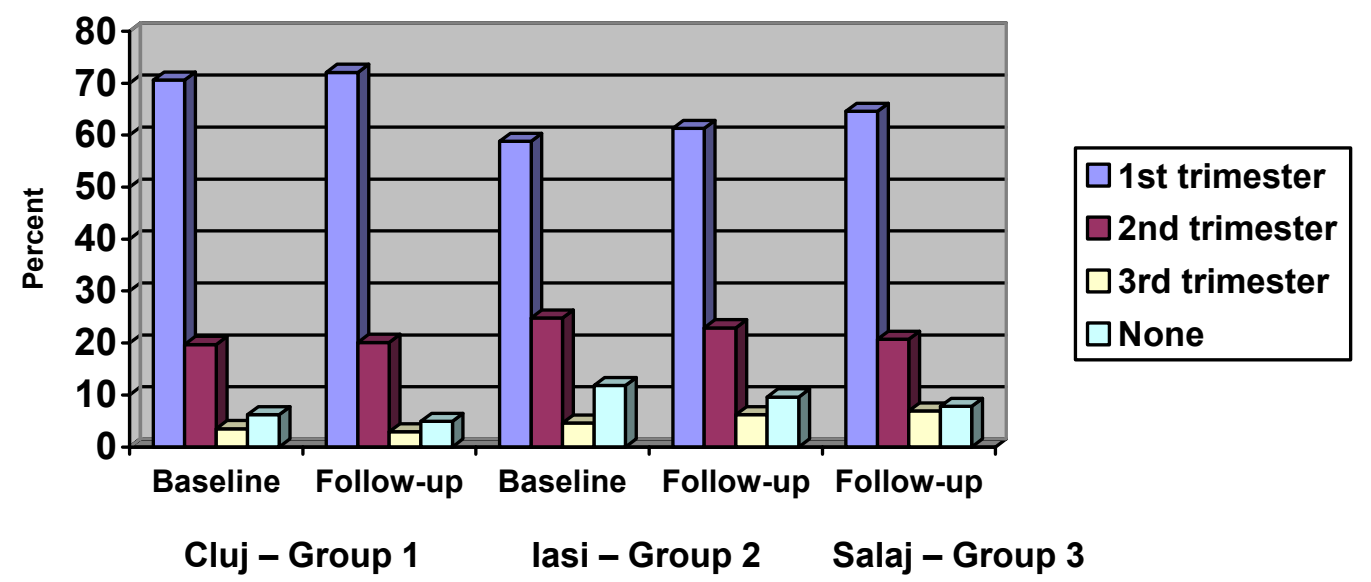

Table 4. Percentage of women who began prenatal care for last pregnancy in first trimester by selected characteristics at follow-up

\begin{tabular}{|c|c|c|c|}
\hline & Cluj-Group 1 & lasi-Group 2 & Salaj-Group 3 \\
\hline & $N=152$ & $\mathrm{~N}=130$ & $\mathrm{~N}=150$ \\
\hline \multicolumn{4}{|l|}{ Age Group } \\
\hline 15-24 & 70.4 & 66.8 & 61.3 \\
\hline $25-34$ & 76.8 & 60.4 & 67.1 \\
\hline $35-44$ & 69.9 & 55.1 & 66.5 \\
\hline \multicolumn{4}{|c|}{ Level of Education } \\
\hline Primary & 51.0 & 54.3 & 47.9 \\
\hline $\begin{array}{l}\text { Secondary } \\
\text { incomplete }\end{array}$ & 75.1 & 58.3 & 68.2 \\
\hline $\begin{array}{l}\text { Secondary } \\
\text { complete }\end{array}$ & 74.4 & 60.2 & 66.1 \\
\hline College & 79.8 & 71.2 & 70.6 \\
\hline \multicolumn{4}{|c|}{ Socioeconomic Status } \\
\hline Low & 50.6 & 40.1 & 41.4 \\
\hline Medium & 66.7 & 64.3 & 66.2 \\
\hline High & 88.7 & 68.9 & 74.7 \\
\hline
\end{tabular}

Use of contraceptive methods. The percentage of women currently using a family planning method at baseline and follow-up is shown in Figure 6. Reported use is presented by selected demographic characteristics in Table 5. The use of modern methods slightly increased in the Cluj area from 34 to 36 percent. A greater increase was found in Iasi area, 
from 26 to 31 percent. However, an increase in the use of a modern method was higher in the control area (Salaj) at 45 percent. It is not possible to determine if the figure changed during the study period. For these groups, at the follow-up, the most reported modern methods were the IUD, the condom, and the pill, although the most frequently mentioned method was different for each group. The overall proportion of women currently using a modern method varies slightly by selected characteristics. In Cluj, the use of modern methods is higher among 15 to 24-year-olds (41\%), among those with secondary education $(51 \%)$, and with high socioeconomic status $(51 \%)$. In the Iasi area, the use of modern methods is higher among 35 to 44 -year-olds (44\%), for those with secondary education (51\%), and among those with middle socioeconomic status (40\%). In the Salaj area, the use of modern methods is higher among 25 to 34 -year-olds $(61 \%)$, for those with secondary or higher education (60\%), and among those with high socioeconomic status (72\%).

Figure 7. Percentage of women currently using a family planning method at baseline and follow-up

\section{Family Planny Use}

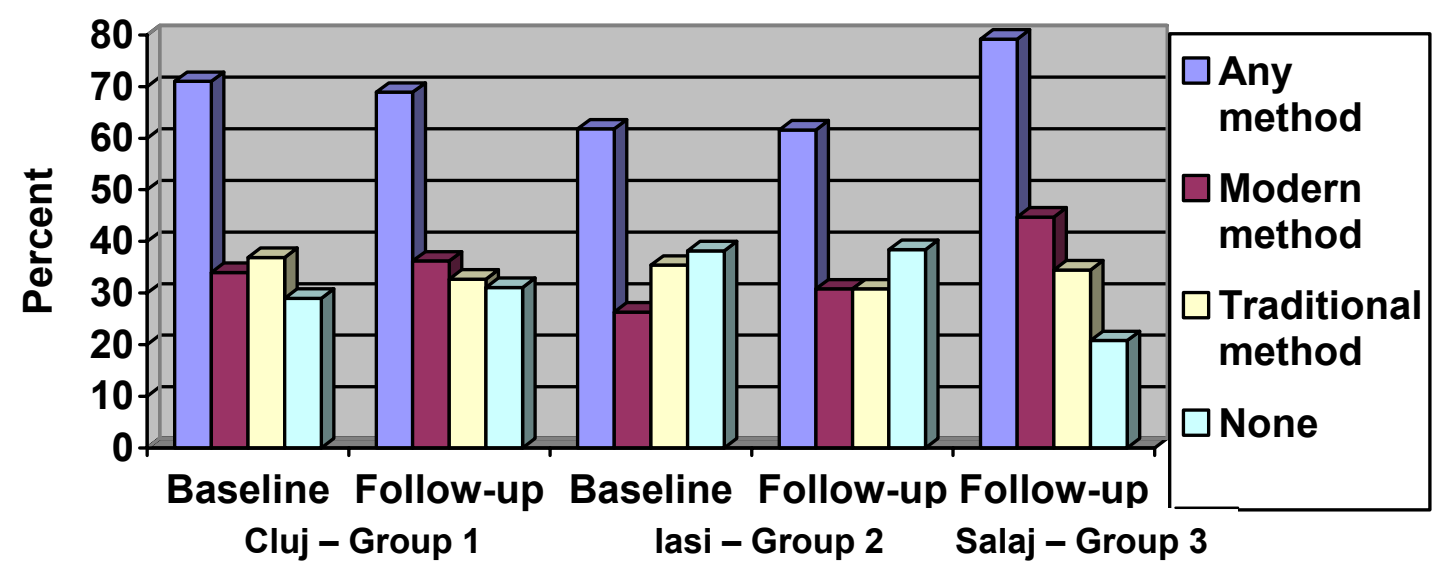

Figure 8. Percentage of women using modern contraception, by method

\section{Family Planning Use, By Method}

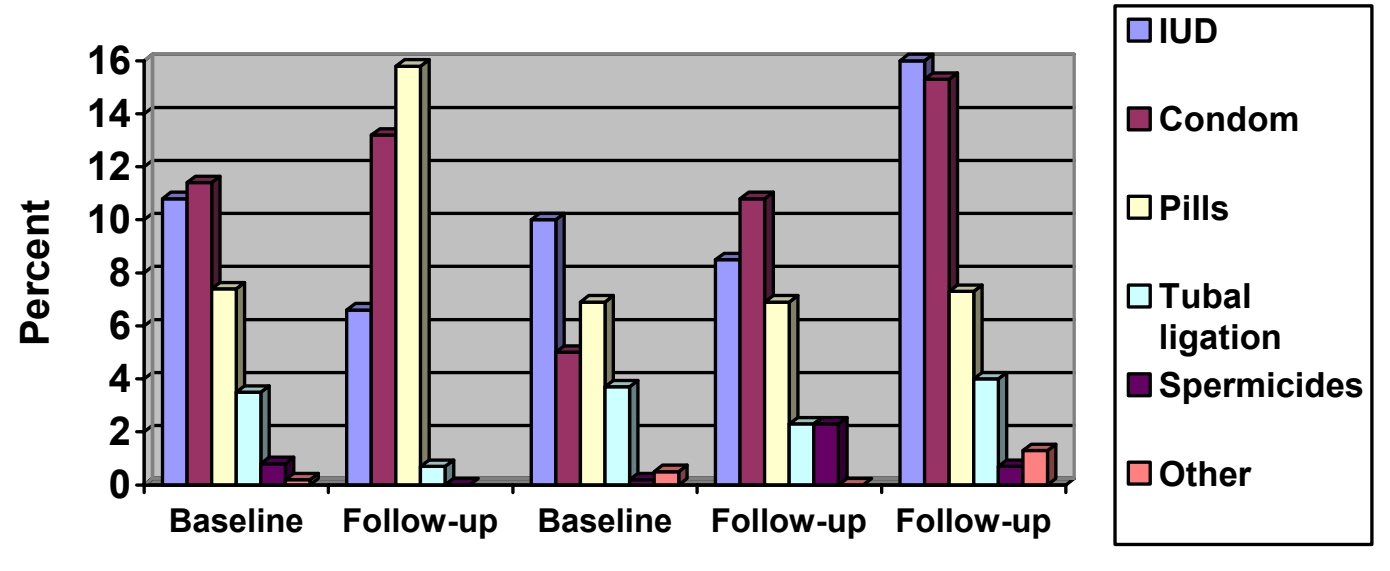

Cluj-Group $1 \quad$ lasi-Group 2 Salaj-Group 3 
Table 5. Percentage of women using a modern method of contraception by selected characteristics at follow-up

\begin{tabular}{|c|c|c|c|}
\hline & Cluj-Group 1 & lasi-Group 2 & Salaj-Group 3 \\
\hline & $\mathrm{N}=152$ & $\mathrm{~N}=130$ & $\mathrm{~N}=150$ \\
\hline \multicolumn{4}{|l|}{ Age Group } \\
\hline $15-24$ & 40.6 & 16.0 & 24.4 \\
\hline $25-34$ & 30.4 & 36.8 & 61.0 \\
\hline $35-44$ & 35.0 & 44.2 & 42.0 \\
\hline \multicolumn{4}{|c|}{ Level of Education } \\
\hline Primary & 8.3 & 0.0 & 9.4 \\
\hline $\begin{array}{l}\text { Secondary } \\
\text { incomplete }\end{array}$ & 16.7 & 15.9 & 40.5 \\
\hline $\begin{array}{l}\text { Secondary } \\
\text { complete }\end{array}$ & 51.4 & 51.1 & 60.6 \\
\hline College & 36.7 & 47.6 & 60.0 \\
\hline \multicolumn{4}{|c|}{ Socioeconomic Status } \\
\hline Low & 10.0 & 20.8 & 8.6 \\
\hline Medium & 35.0 & 40.0 & 47.4 \\
\hline High & 50.8 & 33.3 & 72.5 \\
\hline
\end{tabular}

Breast self exam. Figure 9 and Table 6 show the percentage of women with knowledge about breast self-exams (BSE), by group, and demographic characteristics, respectively. Significant increases were noted in the two treatment areas between the baseline and follow-up surveys. Women in the control area are just as likely as those in the two treatment areas to know about BSE at follow-up.

Figure 9. Percentage of women with knowledge about breast self-exams at baseline and follow-up

Heard of Breast Self-exams

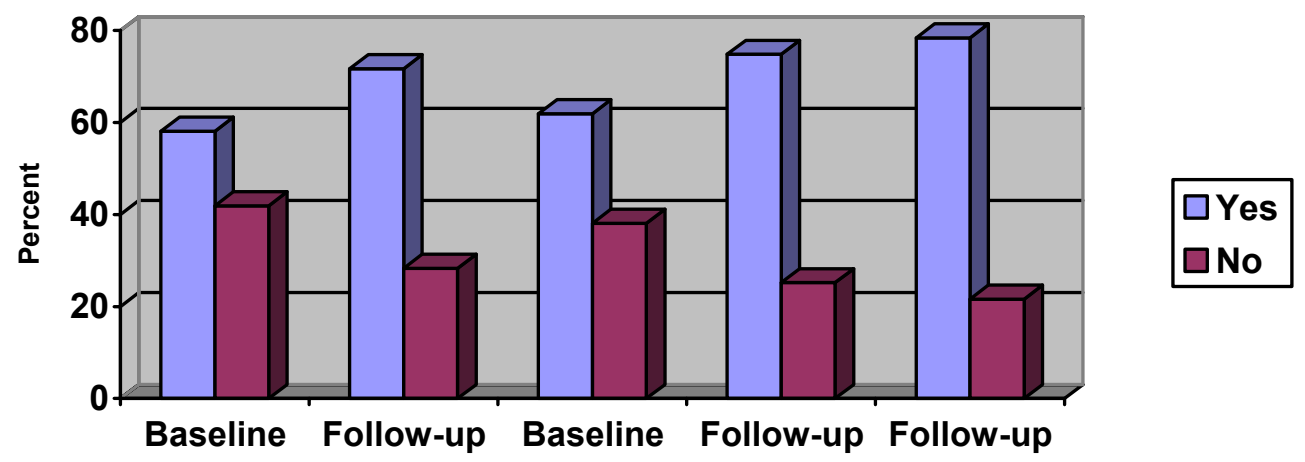

Cluj-Group $1 \quad$ lasi - Group $2 \quad$ Salaj-Group 3 
Table 6. Percentage of women who have heard of BSE by selected characteristics at follow-up

\begin{tabular}{|c|c|c|c|}
\hline & Cluj-Group 1 & lasi-Group 2 & Salaj-Group 3 \\
\hline & $\mathrm{N}=152$ & $\mathrm{~N}=130$ & $\mathrm{~N}=150$ \\
\hline \multicolumn{4}{|l|}{ Age Group } \\
\hline $15-24$ & 65.6 & 56.0 & 63.6 \\
\hline $25-34$ & 80.9 & 97.4 & 82.9 \\
\hline $35-44$ & 72.5 & 77.3 & 86.0 \\
\hline \multicolumn{4}{|c|}{ Level of Education } \\
\hline Primary & 17.4 & 40.0 & 53.6 \\
\hline $\begin{array}{l}\text { Secondary } \\
\text { incomplete }\end{array}$ & 62.5 & 65.9 & 80.1 \\
\hline $\begin{array}{l}\text { Secondary } \\
\text { complete }\end{array}$ & 85.1 & 90.9 & 85.0 \\
\hline College & 90.0 & 95.5 & 88.0 \\
\hline \multicolumn{4}{|c|}{ Socioeconomic Status } \\
\hline Low & 33.3 & 59.6 & 59.4 \\
\hline Medium & 71.7 & 83.3 & 84.1 \\
\hline High & 91.7 & 89.5 & 82.9 \\
\hline
\end{tabular}

Figure 10 shows the frequency of BSE among women who have heard about BSE at baseline and follow-up. Significant changes in frequency of performing a self-exam were found among women who are now reporting breast self-exam (ever) between baseline and follow-up.

Figure 10. Frequency of BSE among women who have heard about BSE at baseline and follow-up

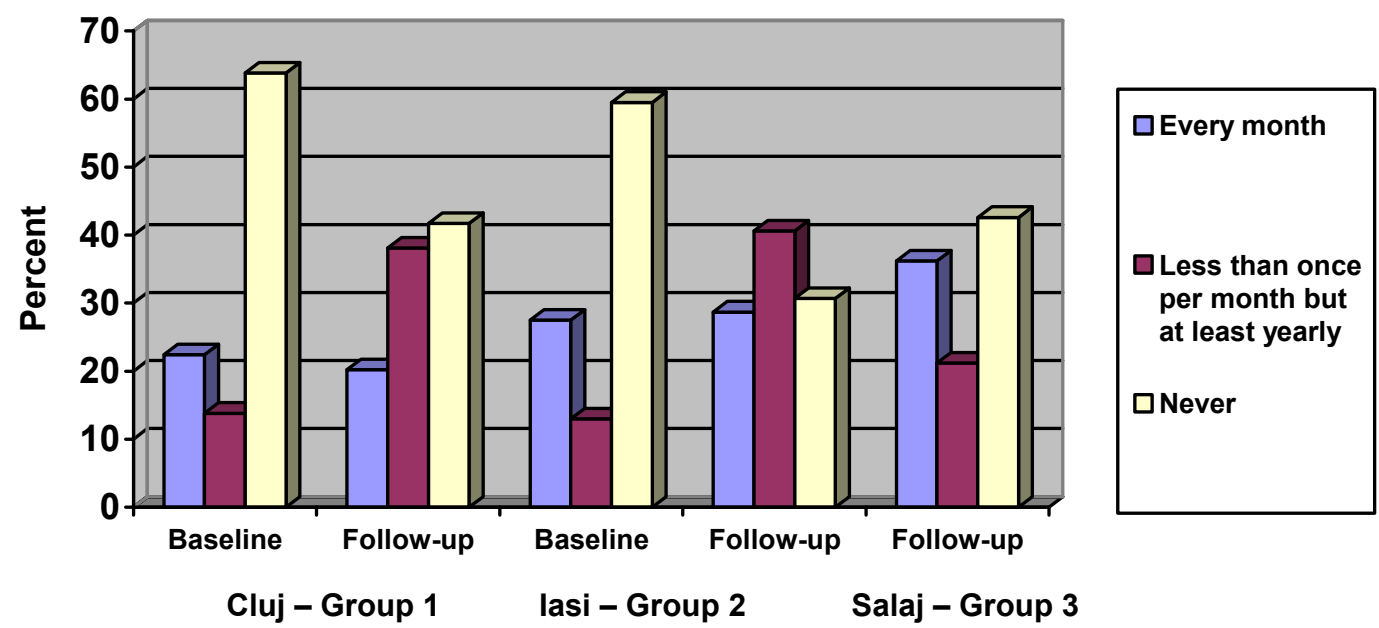

Cervical cancer screening. Women who reported that they ever had a Pap smear decreased, but not significantly, between baseline and follow-up (Figure 11). The few women who reported ever having a Pap smear were more likely to be women of higher socioeconomic status, have a higher level of education, and be somewhat older (data not shown because there are fewer than 10 cases per group). 
Figure 11. Percentage of women who have had a cervical cancer screening test at baseline and follow-up

Have Had Cervical Cancer Test

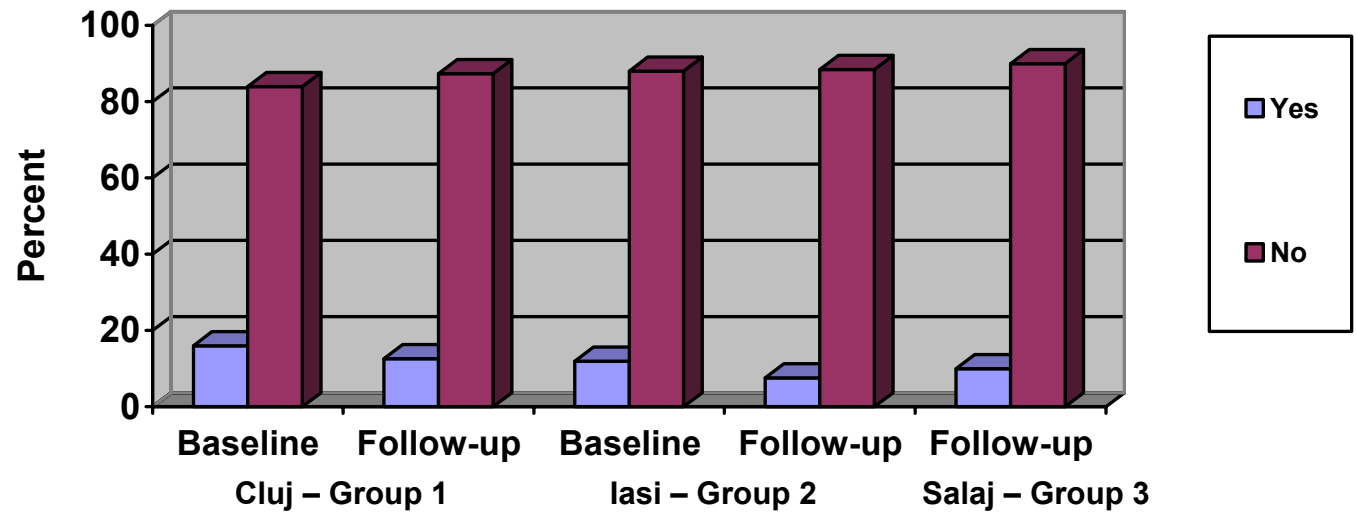




\section{SUMMARY OF FINDINGS}

Pre- and post-test scores and in-depth interview results indicate a dramatic increase in the level of knowledge and self-confidence among health care providers. The data show an improved working relationship between doctors and nurses, better communication with patients, a more systematic approach to providing care, and longer consultation time with pregnant women. Data also suggest that there is room for improvement on pregnancyspecific issues, particularly implementation of an improved referral system, laboratory follow-up, and level of respect and professionalism in all interactions between patients and providers and among providers of different specialties (e.g. GPs and OB/Gyns).

Post-test results showed a 45 percent average increase in knowledge from pre-test scores. The first in-depth interview indicated that three months was the minimum time recommended for exclusive breastfeeding. This figure rose significantly at the second interview. The impact of the PCI/R training on discussing modern contraceptive methods with patients was consistent, and both health care providers and patients appear more comfortable approaching this issue. Yet, increased and continued use of modern contraceptive methods among Romania's population requires additional time and resources to change behaviors learned over the last 50 years, characterized by a lack of respect for women's bodies, ignorance, fear, and shame. The data, nevertheless, show that important improvements have occurred.

Findings show that all providers consistently found breast cancer screening and education to be critically important because most patients delay seeing the doctor until they have a serious health problem. Providers reported that breast examinations are now included in the annual exam.

Data suggest that patient access to specialists poses a major barrier to cervical cancer screening among women of reproductive age, especially among those who live in rural areas. In addition, the poor relationship between the GPs and the OB/Gyn presents another barrier to quality provision of this service. The relationship is commonly marked by a lack of professional courtesy, collaboration, and teamwork.

Findings suggest a lack of provider knowledge and confidence in recognizing signs and symptoms of menopause and in identifying and prescribing appropriate treatment. Cultural beliefs were identified as a principal barrier to seeking information and treatment for menopause-related symptoms. More practical and competency-based provider-training and technical assistance is required on all aspects of menopause, as is targeted dissemination of key information.

In Romania, a culture of accurate and timely patient charting does not exist. It is still illegal for nurses to complete the patient file, thereby putting a greater burden on physicians and reinforcing nurses' lack of empowerment. These realities, among others, suggest that an alternative data collection method or technique may have been more appropriate for exploring the long-term impact of the PCI/R training.

Based on findings from focus groups discussions, the Warmline provider component appeared to add minimal value to the successes noted above. For example, many of the providers did not know how to access the Warmline provider, and the majority of Warmline providers were unclear about their roles and responsibilities. Weaknesses in the Warmline provider component were due to a lack of experience and insufficient time 
preparing Warmline providers about how to support their colleagues and carry out their new responsibilities.

\section{CONCLUSIONS AND LESSONS LEARNED}

There are several conclusions that can be drawn, despite some limitations in the design of the study that make the results less conclusive. They can be divided into three major categories:

1. The basic training intervention

2. The Warmline provider program

3. The research study itself

\section{Basic training intervention}

Overall, the five-day training program increased medical knowledge and behavior among general practitioners and nurses. Findings show that providers in both treatment groups (Cluj and Iasi) demonstrated an increase in their level of confidence as a result of the PCI/R training. This lead to improved trust, better monitoring, and better adherence to new reproductive health guidelines. Patients were found to have begun taking more control of their health and making informed decisions about their health care.

Although the study found that the training resulted in increased KAP for service providers, it also showed that there is room for improvement. The in-depth interviews and focus group discussions indicated the need for a vastly improved referral system, improved laboratory follow-up and, most of all, increased respect and quality in all interactions between patients and providers, and greater collegiality among providers of different specialties (e.g. GPs and OB/Gyns).

"One problem difficult to address is the great difficulty many providers have in accepting change. This is often viewed as a threat and insult to the professional capabilities of doctors and nurses older in age, and with many years of practice." [Medical provider, Bucharest]

There need to be more programs on pregnancy-specific issues, such as anemia; vitamin prophylaxis; and promotion of healthy lifestyles limiting intake of alcohol, smoking, and medication. In addition, training is needed on taking a careful and exhaustive personal history to identify risk factors for mother and fetus, accurate referral criteria and follow-up systems, and good laboratory analysis follow-up.

Findings suggest that Pap smear testing does not need as much emphasis as do efforts to improve screening programs and resolve access issues. Transportation for patients to the nearest specialist's office is problematic among poor, isolated, and rural women. One possible solution would be to arrange for the collection of samples locally by trained GPs. The relationship between GPs and OB/Gyns must also be improved. The MoHF might consider legally imposing a referral system, thus obligating OB/Gyns to perform appropriate testing and treatment and to collaborate with their GP colleagues in exchanging information and establishing accurate follow-up procedures.

Additional training and assistance needs to be provided to family physicians and nurses on all aspects of menopause including signs, symptoms, and treatment. This research documented a lack of awareness both in recognizing the symptoms and in indicating 
appropriate treatment. Lack of information and confidence in prescribing treatment makes providers reluctant to diagnose, preferring instead to refer patients to a specialist. Targeted and pre-tested materials need to be developed and disseminated to the medical community. Along with economic reasons, providers indicated that cultural beliefs are strong barriers to seeking information and treatment for menopause related symptoms.

\section{Utilization}

Based on the OR results, $\mathrm{PCI} / \mathrm{R}$ has made internal changes in how programs are designed, implemented, and evaluated:

- Modifications to HP-HC training program: PCI/R modified the HP-HC training program to change the classroom-style training to one-on-one mentoring for providers at the clinic by reproductive health specialists. The specialists worked side-by-side the medical providers to diagnose and treat patients with complex and difficult clinical cases on pre- and postnatal care, menopause, cervical cancer screening and follow-up, breastfeeding, family planning, and STIs. The goal of the practicum was to provide additional targeted information and skills to better treat complex cases.

- Incorporating OR lessons learned: PCI/R was awarded funding from the European Union for their "Bridging Services for Romania's Underserved Populations" project, which aims to improve access to sustainable health care and to improve social services through an innovative, community-based social and health care delivery model in underserved rural areas. Improving access was one of the key weaknesses identified in the OR study.

- Pending proposals incorporating OR lessons learned: $\mathrm{PCI} / \mathrm{R}$ has completed a proposal titled "Healthy Beginnings" to address the needs of Romanian women of reproductive age. The project cuts across disciplines and sectors, with an emphasis on integrated, comprehensive behavior change by both providers and beneficiaries. "Healthy Beginnings" will consider all stages of reproductive health including preconception, prenatal care, perinatal care, neonatal care, and postnatal care. Fundamental crosscutting initiatives, continuum of care approaches, critical thinking skills, and improvements in attitude, such as client-centered quality of care, are built into every program component.

\section{Key achievements related to the training program}

- As a direct result of the PCI/R training, the Open Society Foundation Training Center (Soros Center) in Cluj has contracted with over half of the trainers trained by PCI/R to continue to conduct regional training courses in reproductive health for medical providers. It can be considered an accomplishment of the project that there are now 41 reproductive health trainers with over 2,000 hours of training experience in adult learning techniques who are available to continue and expand training activities in other programs.

- The HP-HC training curricula on pre- and postnatal care, menopause, nutrition and healthy lifestyles, and genital and breast cancer prevention and screening have been disseminated to seven additional counties, in addition to the MoHF, the NGPA, and the Nurses Association. 


\section{The Warmline provider program}

Based on the findings of the focus group discussions, the Warmline provider component added minimal value to the successes noted above. Weaknesses in the program were due to the lack of experience and time needed for the providers to understand how to support their colleagues and carry out their new responsibilities. Many of the providers did not know how to access the Warmline provider, and the Warmline providers themselves were unclear about their roles and responsibilities. These issues seemed possible to address, and $\mathrm{PCI} / \mathrm{R}$ felt that this component had enough potential to warrant further investment. Fortunately, data from the study was available early enough in the program to dramatically modify the Warmline provider program during the intervention. They addressed these weaknesses through the following new activities:

- Training of trainers: PCI/R organized a second training of trainers (ToT) course to further develop leadership, communication, management, counseling, and facilitation skills. The ToT was hands-on and interactive, with direct involvement from participants. Exercises and practical examples were based on the daily experiences that occur in the dispensaries. These same training skills were also provided to the local coordinators to strengthen their abilities to supervise the Warmline provider program.

- Skill building: The local coordinator was tasked with aiding the Warmline providers through individualized supervision and support, as well as monthly meetings with the entire team. The local coordinator completed an assessment of each provider that included quality and efficiency of work, follow-up on specific tasks and responsibilities, job knowledge, ability to effectively communicate, finding new and better ways to solve problems, motivation, and understanding their role.

- Strengthening the relationship with other providers: Warmline providers strengthened their relationships with other providers in their region through more frequent communication. This increased time commitment was part of their contractual obligation with $\mathrm{PCI} / \mathrm{R}$. They also became valuable resources for local coordinators in planning and implementing the individualized small group seminars at the dispensaries.

\section{Key achievements related to the Warmline provider program}

- Local and national NGOs have established contact with the Warmline providers in Cluj to continue the work started by PCI/R.

- Despite conclusion of the HP-HC program, the Warmline providers have continued to meet together independently, at their own expense, to discuss specific cases, share information, network, and even host small group meetings around a particular topic area.

- The Warmline provider curricula has been disseminated to the MoHF, the NGPA, the Nurses Association, and various donors.

"Now it's different. The Warmline providers ask to meet more often. I see a big difference in just six months. They [Warmline providers] have developed friendships with the other doctors. They talk about their cases, and they are beginning to refer. The Warmline provider now links one doctor with another. It's really working." [Local Coordinator, Cluj Project] 


\section{The research study}

$\mathrm{PCI} / \mathrm{R}$ learned a great deal from the conclusions drawn from the research study, as well as from the process itself. The OR study validated PCI/R's overall training approach and provided sufficient information about how to improve it, especially the Warmline provider component. Further study is needed, however, to understand the reasons for some of the more counterintuitive findings. In a few selected topic areas, for example, it is unclear why results did not show significant differences between intervention groups and the control group. Perhaps the intervention and control populations were not comparable (for example, the population of Salaj is smaller than in Cluj or Iasi and has fewer medical providers). $\mathrm{PCI} / \mathrm{R}$ also concluded that chart reviews will continue to provide inaccurate and incomplete data until Romanian health professionals are better trained in medical charting. 


\section{RECOMMENDATIONS}

$\mathrm{PCI} / \mathrm{R}$ learned from the OR study that programs need to cut across disciplines and sectors. One intervention alone - training - is insufficient to make lasting and sustained improvements. Maternal and infant morbidity and mortality cannot be significantly improved unless the underlying causes are addressed through a combined medical, social, and community model. Key elements of such a model would include:

Medical

- The political will, dedication, and institutional support from the top down to support change.

- The National Health Insurance House must change the current system of reimbursement for family physicians in order to motivate them to provide more preventive health care services.

- Increased collaboration between providers needs to be encouraged. Teamwork, support, and information sharing should be an on-going part of the process, built into every intervention.

\section{Social}

- Programs must take into account the extremely poor conditions faced by rural providers and their clients: inadequate salary, insufficient or non-existent medical equipment, lack of renewable supplies, inadequate public transportation, extreme poverty, and harsh winters affect quality and access to care.

- Much of Romania is characterized by extreme poverty, unemployment, underemployment, decreasing life expectancy, poor health outcomes, a large migrant population, and a high child abandonment rate. All human development indicators point to the need for increased services and programs for vulnerable groups.

\section{Community}

- Community reproductive health programs must provide women and men of reproductive age, and pregnant women and their families with a wide range of services. These services should include improved access; counseling; and information on reproductive health, family planning, and attachment and bonding between mother and infant; support groups; medical and social services referrals, and follow-up, among others. Continuous training and education of the general population on health care issues (including rights and responsibilities) is essential in building an effective health care system.

- Community programs must empower women and men with limited access to health information and social services to take control of their health and welfare and to make informed decisions about their health and their children's health.

\section{Dissemination of Study Results}

$\mathrm{PCI} / \mathrm{R}$ will disseminate the results of this study to the MoHF, health policy advocates, local and international NGOs, USAID/Romania, program planners, general practitionioners, nurses, health educators, and specialists. It is PCI/R's hope that partner NGOs and other organizations will provide concrete, practical, and low-cost recommendations to improve reproductive health services in Romania. The findings will be available in a variety of formats, including a summary version, cd-rom, and on appropriate web sites. Efforts will also be made to explore appropriate venues for publishing the results of this study as an example of using data for decision making. 
Accomplishments and lessons learned from the OR study are also being widely disseminated to the PCI Worldwide team through a variety of strategies:

- The PCI/R Country Director delivered an interim OR report at the PCI Annual Meeting in January 2002.

- Country directors from PCI's 12 field programs held a roundtable discussion at the annual Global Leadership Conference in January 2003. PCI staff work closely with more than 40 local NGOs in 10 other countries and the United States.

- The OR study was presented at PCI's "Sexual and Reproductive Health Institution Strengthening Workshop" in 2003.

- The project report was submitted in an updated version of PCI's "Toolkit on Sexual and Reproductive Health."

\section{Further Research Needed: Training and Programmatic}

\section{As a result of this research, $\mathrm{PCI} / \mathrm{R}$ recommends that several additional studies be completed, included the following:}

- Retest the hypothesis of the Warmline provider program now that PCI/R has made significant improvements and modifications to the original concept. The study should include a cost-benefit analysis.

- Conduct an additional study of the relationship between the KAP of providers, including confidence and respect for clients, and actual behavior changes among women and men of reproductive age at the community level.

- Conduct a study on how to best measure the impact of political and institutional will among those in political positions and administrations including directors and linesupervisors to support infrastructure and policy changes in the preventive and reproductive health care areas. The study could compare qualitative data gathered through focus group discussions and in-depth interviews to measure the impact of political will.

- Conduct a best practices study to learn what works in designing programs aimed to increase collaboration between providers including, teamwork, support, and information sharing, particularly among medical providers from various disciplines (e.g. OB/Gyns, GPs, pediatricians) and from different hospitals and medical settings. Several different approaches could be compared including focus group discussions and in-depth interviews. 
"Because of the PCI training, I feel more self-confident, and my surveillance of pregnant women has improved. More than three-quarters (of my pregnant women clients) visit the clinic monthly. I follow the development of the unborn child more systematically. I improved my treatment in many ways." [Doctor, Iasi, first in-depth interview]

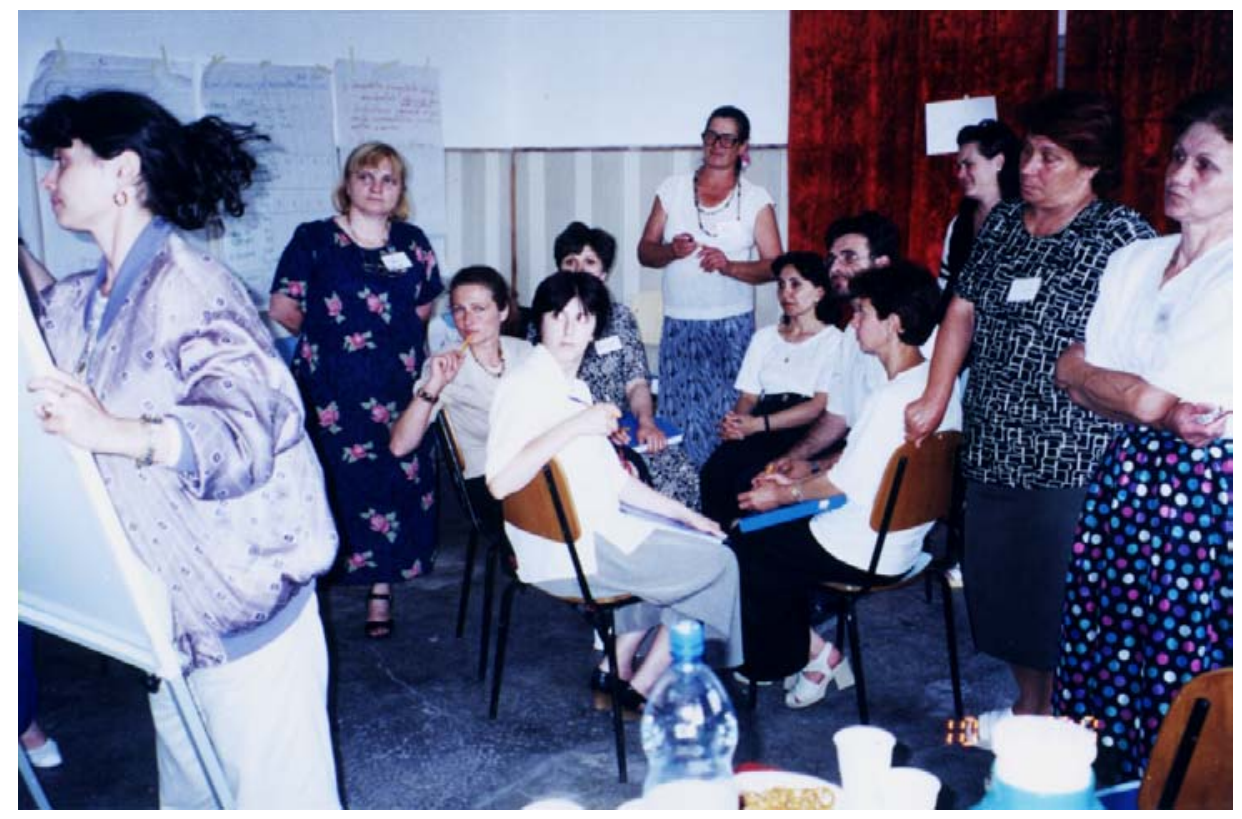

Training Course, Iasi County, March 2000 


\section{Roster of agencies that will receive the $\mathrm{OR}$ report}

- John Snow International/Romania

- Open Society Foundation/Romania

- National Midwifery Association of Romania

- National General Practitioners Association of Romania

- Johns Hopkins University Center for Communication Programs

- Family Health International

- U.S. Department of Health and Human Services, Administration on Children, Youth, and Families

- Department for International Development

- The Centre for Development and Population Activities

- U.S. Centers for Disease Control and Prevention Information Network

- American Public Health Association, Education Services

- United Nations Development Programme/Romania

- UNFPA: United Nations Population Fund/Romania

- AVON Cosmetics/Romania

- UNICEF United Nations Children's Fund/Romania

- Population Services International/Romania

- JHIEGO Corporation

- American International Health Alliance 